\title{
DESTINATION COMPETITIVENESS CHALLENGE: A UGANDAN PERSPECTIVE
}

\begin{abstract}
This paper analyses and explicates the limiting role of multiple and varied challenges in the realisation of a country's tourism potential using Uganda as an exemplar. Two objectives are pursued, one that entails an assessment of the competitive potential of Uganda's tourism and another, an explication of the challenges that limit its full realisation. The study is based on secondary data supplemented through in-depth interviews with some key informants in Ugandan tourism. The paper identifies disparities in destination product and demand patterns, inadequate marketing budgets in the face of a persistent negative image and inadequate institutional and managerial capabilities as key challenges. It concludes that the complexity of challenges faced by Uganda, a non-traditional destination, makes the notion of competitive advantage used in conventional strategy and tourism destinations competitiveness literature seem inappropriate. This has implications for tourism development and management in such destinations with particular focus on resource allocation and utilisation.
\end{abstract}

Key words: Competitiveness challenge, tourism in Uganda, destination competitiveness, nontraditional destinations, competitive parity 


\subsection{INTRODUCTION}

Most developing countries are drawn to tourism with the rich allure of deriving benefits such as the inflow of foreign direct investment, foreign exchange, increasing employment prospects, and crucially, alleviating poverty in order to achieve sustainable development (Akama \& Kieti, 2007; Lea,1988; Mbaiwa, 2005). In an increasingly globalised world, the intensification of competition among nation states, regions and cities directly influences the markets (goods and services), investment decisions, the flow of talents, travel and visitation patterns among other things (Anholt, 2007; Buhalis, 2000). This implies that prospective tourists have a wide variety to choose from in terms of their travel needs, whether these are for business or leisure purposes, and most destinations are substitutable. The question of how, destinations that have no historical precedence for tourism and ones that face several, complex challenges can effectively compete and succeed in such an environment ought to constitute an important area of inquiry in tourism studies.

The aim of this research is to provide a context-specific description, analysis, and explication of the competitive challenges facing Uganda as a tourism destination within Sub-Saharan Africa (SSA) and the East African (EA) region. It attempts to answer the question why and how, despite the various and on-going interventions, and the possession of unique tourism resources, Uganda struggles to gain competitiveness within the region. In so-doing, two specific objectives are pursued. First, the study assesses the competitive potential of Uganda's tourism by examining the most recent trends in the sector and the region. Secondly, it analyses and explicates what are perceived to be some of the competitive challenges facing Uganda's tourism sector in order to contextually demonstrate their role in limiting the attainment of competitiveness in this non-traditional destination.

The term "non-traditional" destination is used here arbitrarily to depict those destinations in a developing country context, which do not have a well-developed conventional tourism product (e.g. sun, sand and sea) or a highly developed and marketed niche tourism product. Such destinations have the potential to develop conventional or niche forms of tourism and there are indicators in place, for instance, the steady increase in annual tourist arrivals and expenditure as well as a plethora of mostly natural and cultural tourism resource base. However, such non-traditional destinations remain relatively unknown in the global tourism industry, their tourism market shares are significantly low compared to their resource potential; hence, their capacity to benefit from tourism development is limited (cf. De Holan \& Phillips, 1997).

A tourism destination is variously defined by different authors. A few examples include an area that contains a critical mass of development that has the potential to satisfy traveler needs (Gunn, 1994), or a place that a tourist has an intention to visit, owing to its attractions (Keller, 1998). The attractions might exist prior to the phenomenon of tourism or are purposively created to fulfill its objectives 
(ibid). A destination is also considered to be an amalgamation of tourism products that offer an integrated experience to prospective tourists (Buhalis, 2000). Similarly, Vanhove (2012, p.21) defines a destination as 'a specific geographic area under one or more government authorities, that draws visitors from a substantial distance away by its attractions and provides paid accommodation facilities'. However, as noted by Buhalis (2000, p.97), 'it is increasingly recognised that a destination can also have a perceptual element which can be interpreted subjectively by consumers depending on their travel itinerary, cultural background, purpose of visit, education level and past experience'. These definitions reflect a geographical interconnectedness between socioeconomic, perceptual and spatial characteristics of a place and its potential to meet multiple and varied needs of prospective tourists. It is in this relatively wider sense that the destination concept is used throughout this paper. The rest of the paper is structured as follows: first, a review of the relevant literature is presented; followed by study context and methods, an in-depth analysis and discussion of the study findings and the concluding remarks.

\subsection{THEORY}

The past decade has seen unprecedented interest in the notion of a tourism destination competitiveness (TDC) within the academe, as evidenced in several publications on the topic (e.g. Claver-Cortes et al., 2007; Crouch \& Ritchie, 1999; Dwyer et al., 2004, 2009; Enright \& Newton, 2004; Mazanec et al., 2007; Ritchie \& Crouch, 2003, 2011), including a special journal issue in Tourism Management in 2000 (Volume 21, Issue 1). What might justify this remarkable interest in TDC is the observation that some previously well established tourism destinations are increasingly being perceived as unsustainable while others are on the verge of decline (Agarwal, 2002; Zhang \& Jensen, 2007), unless major rejuvenation and market re-adaptation efforts are prioritised (cf. Mazanec et al., 2007). But, a more poignant rationale is the increasing global competition, and, the realisation that many more destinations continue to emerge, offering the contemporary tourists variety of choice (e.g. Buhalis, 2000; Dwyer, et al., 2009).

Besides, there is now an increasingly sophisticated demand side that comprises experienced tourists whose lifestyles favour flexibility and independence over standardisation (Claver-Cortes et al., 2007; Dwyer et al., 2009). This complexity in tourism demand is further exacerbated by the availability of information, facilitated by the advances in information and communication technology (ICT) (Buhalis \& Law, 2008), the prevalence of social media used in online information sharing (Xiang \& Gretzel, 2010 ) and the perceived influences of electronic word of mouth (eWOM) on consumer behaviour (Sparks et al., 2013). However, the global tourism demand patterns, undeterred by these changes, continue to manifest an intriguing paradox in which very little has changed in terms of the top ten tourism destinations in the last decade (UNWTO, 2013). The commentaries in the extant literature (cited previously) have in various ways, sought to identify and explain what makes some destinations 
more competitive than others and what (if any) can be done to attain a competitive edge. The framework adopted in most cases focuses on strategic management literature, particularly the work of Michael Porter (1990), with an implied acceptance of Kotler's (1998) observation that there are parallels between the administration of a country and that of a business and that both can benefit from strategic management approach.

Three main TDC frameworks that are perceived to be "universally applicable" are briefly discussed in this section. It must however be noted that a detailed discussion of the TDC models falls outside the scope of this paper, but reference can be made to Hassan (2000), Dwyer et al (2004), Ritchie and Crouch, (2003, 2011), Mazanec et al (2007) for such purposes. Whilst seeking to understand the behaviour of firms in relation to national competitive advantage, Porter considered the question 'why do firms based in particular nations achieve international success in distinct segments and industries' (Porter, 1990, p. 18)? Here, Porter developed the so-called national diamonds, a framework for analysing the external environment and one that has been recontextualised into some TDC analysis, with crucial insights into its significance and limitations (e.g., Buhalis, 2000; Claver-Cortes et al., 2007; Crouch \& Ritchie, 1999; Ritchie \& Crouch, 2003, 2011). These studies underscore the importance of competitive strategies, i.e. 'the search for a more favourable competitive position within an industry' (Buhalis, 2000, p.104) as an imperative that any firm (or destination) ought to possess. And yet, the notion of competitiveness is inherently difficult to measure (Crouch \& Ritchie, 1999), particularly when applied to a tourism destination as opposed to a conventional firm (ClaverCortes et al., 2007).

Competitiveness in a tourism destination context means different things to different people, it is not a concept that is objectively defined and understood (e.g. Hassan, 2000; Ritchie \& Crouch, 2003, 2011). For instance, destination competitiveness, to Hassan (2000) entails its ability to create value-added tourism products, sustain the resource base and to ensure it has and thus maintains a superior market position relative to competitors. Meanwhile to Enright and Newton (2004, p.778), it entails the destination's ability to 'attract and satisfy potential tourists [such that] competitiveness is determined both by tourism-specific factors and a much wider range of factors that influence the tourism service providers'. In both cases, competitiveness remains a subjective concept that is defined based on contextual variables (resource base, tourists, service providers, other factors, etc).

The most insightful re-conceptualisation of Porter's national diamonds to an analysis of TDC can be found in Crouch and Ritchie (1999) and Ritchie and Crouch (2011). These authors assert that TDC is influenced by five main components. The first of these includes core resources and attractors, that comprise the primary elements of destination appeal and hence the key motivators for visiting a particular destination, (e.g. the physiography and climate of a destination, cultural and historic attractions, the market ties with originating countries, special events, tourism superstructure, and the 
range of activities) (Crouch \& Ritchie, 1999, p.146-148; Ritchie \& Crouch, 2011, p.341-342). The second component entails the supporting factors and resources which exert a more less secondary influence by providing a firm foundation upon which a successful tourism industry can be established, (e.g. tourism infrastructure, political will and accessibility)', (Crouch \& Ritchie, 1999, p.148-149; Ritchie \& Crouch, 2011, p.343-344). They emphasise that 'a destination with an abundance of core resources and attractors but a dearth of supporting factors and resources, may find it very difficult to develop its tourism industry at least in the short term, until some attention is paid to those things that are lacking' (2011, p.343).

Here, international tourists' quest for experiencing different cultures, landscapes and wilderness whilst remaining unwilling to relinquish the familiar comforts and security of the home environment (Azarya, 2004) exacerbates the competitive challenge in destinations lacking adequate supporting factors. Such demand factors, coupled with inadequate supporting factors constitute one of the main areas in which developing countries would normally aim to attract foreign direct investment (FDI) in tourism (e.g. Azarya, 2004; Endo, 2006). Yet the determinants of FDI are strikingly similar for tourism and non-tourism industries in that they depend on 'cultural/geographic/historical distance, political or economic risk, level of development, privatisation of the industry, liberalisation of FDI regime, availability of hard and soft infrastructure (e.g. roads, airports, electricity, knowledge etc)' (Endo, 2006, p.601). It can therefore be inferred that a destinations' inability to provide such supporting factors and also to attract the required FDI that might address the lack of some of these factors compounds its competitiveness challenges in the short to medium term.

The third dimension (not previously explored in the 1999 publication) focuses on destination policy, planning and development which may be a strategic or policy-driven framework that underpins the nature, scope and direction of tourism development and the expected outcomes of such a development (Ritchie \& Crouch, 2011). This dimension underscores the significance of a common understanding amongst the tourism stakeholders about the framework, what it is meant to achieve, how this can be translated into a strategic vision for the destination ( $(\mathrm{bid})$. It also entails an analysis of the destination's current competitive position within the market as well as a process by which prospective outcomes of the strategic or policy framework can be monitored and evaluated (ibid). The fourth dimension reflects on the role of destination management which comprises those activities that can enhance the appeal of the core resources and attractors and strengthen the quality and effectiveness of the supporting resources inter alia, (e.g. the marketing of the destination, the service experience, availability of financial and venture capital, crisis management, information/research, human resource development and resource stewardship). 
Here, the role of destination management presumes the existence of an entity with the mandate to manage a given destination (cf. Kotler, 1998). Such an entity that hitherto, went by the label destination marketing organisation or increasingly destination management organisation (DMO) has mostly been responsible for marketing a given destination (Kozak \& Baloglu, 2011). However, the DMOs' role is being expanded to include the need to espouse and effectuate the strategic goals of the destination as well as unifying and satisfying various stakeholders (e.g. Beritelli et al., 2014; Bornhost et al., 2010; Kozak \& Baloglu, 2011). Subsequently, the role of destination management and thus the DMO remains a contentious one. On the one hand, the DMO is, for instance, associated with a successful destination (e.g. Bornhost et al., 2010) and on the other, the reference to management in DMO connotes a level of control and influence over a destination's resources, a situation that applies to a very small proportion of DMOs (e.g. Pike, 2013).

The fifth and final dimension entails the qualifying and amplifying determinants or situational conditions whose effect on a destination may define its scale, limit or potential, (e.g. its geographical location, interdependencies on other destinations, safety and security, awareness and image, the overall cost/value, as well as its carrying capacity) (Crouch \& Ritchie, 1999; Ritchie \& Crouch, 2011). They conclude that the 'TDC model is an example of a systematic approach that can strengthen a destination's ability to compete effectively in the international market place, with a potential to lead directly to a sustainable improvement in the quality of life of destination's residents' (1999, p. 150), whilst conceding that 'any model is a simplification of reality, as such, [it may be] incapable of fully capturing the complexities of a tourism destination and its performance' (2011, p.348).

Subsequently, and in spite of the wide recognition and significance of this TDC framework for tourism destination policies and practices (e.g., Beeton, 2005; Dwyer \& Kim, 2003; Enright \& Newton, 2004; Ritchie \& Crouch, 2011), it leaves some theoretical and contextual lacunae when drawn upon to analyse specific, non-traditional tourism destinations such as Uganda that exhibit multiple and complex challenges. In other words, various contextual factors influence a destination's ability to gain from its resource endowments (e.g. De Holan \& Philips, 1997). The model in its "universal" sense does not adequately account for how situational conditions (or chance events) might, for instance, influence a non-traditional destination's quest for competitiveness. A more profound and relevant critique of the TDC model stems from an observation by Beeton (2005) who reviewed an earlier version of this framework. Here, Beeton expresses concerns over the fact that '...Ritchie and Crouch focus on a tourism specific model that appears to come primarily from research undertaken in developed countries...' (p.295), adding that ' ...it would be interesting to test [it] in developing countries...' (p. 296).

While some issues discussed in the model (e.g. the existence of core resources and attractors, development of supporting resources and the political will to develop tourism) do not necessarily have 
to be different for developed and developing countries, the qualifying or situational determinants need a particular focus. Here, the old argument that 'firms and nations face very different challenges as they move from resource to knowledge-based economies' (Dwyer \& Kim, 2003, p373) becomes particularly relevant in contexts where nations have barely crossed the threshold of being competitive based on their resource-endowments. Besides, a common conceptual and epistemological critique of this model has been the inadequate explication of the ambiguous nature of competitiveness (e.g. Dwyer \& Kim, 2003) and the observation that the model appears to be 'a system of definitional rather than cause and effect relationships' (e.g. Mazanec et al., 2007, p.88).

This is where Dwyer and Kim (2003) initially developed their competitiveness model that essentially synthesised or integrated the main elements of competitiveness found in the general and tourism specific literature (Crouch and Ritchie's model in particular), in addition to proposing some (flexible) indicators of competitiveness. Like Crouch and Ritchie (1999) before them, the model comprises five main elements, i.e. resources (endowed/inherited \& created); enabling factors or supporting resources (general infrastructure, quality of service, accessibility of the destination, market ties etc); situational conditions (i.e. the operating environment $\&$ the remote or external environment); destination management (based on activities undertaken by the public and/or private sector); and, demand conditions (comprising three elements, i.e. awareness, perception \& preferences).

The addition of demand conditions and the indicators of competitiveness that are considered to vary from destination to destination in different combinations gives Dwyer and Kim's (2003) model a more universally applicable status than its predecessor. However, in this present research, a number of weaknesses are identified. For instance, what evidence underpins the presumption that matching destination's product with evolving consumer preference will in the first instance lead to competitiveness under the demand conditions for non-traditional destinations? Here, the question of how many of the key attributes of the TDC must be present or absent in a destination for it to be competitive or indeed which are the most important attributes within the model is taken for granted, an issue that has recently been revised and elaborated on by Crouch (2011). It therefore seems inappropriate to invoke the quest for competitiveness in non-traditional destinations prior to answering such questions in the first instance.

Put differently, but within the context of the current research, questions arise with regard to what proportion or combination thereof these determinants, enable a destination to attain competitive advantage. What if any, is the influence of chance events or government or situational conditions on the overall TDC, e.g. the history of a destination, its politics, it culture, its image constructed and perpetuated through a multiplicity of internal and external events? What, if any, might be the prospect of some of these determinants having neutral effects on the competitiveness of a destination? An 
important way of broadening the scope of the TDC to encompass non-traditional destinations entails a reflection on one or more of these questions. Further still, the interest in competitiveness or lack thereof non-traditional destinations is supported by an earlier work by De Holan and Phillips (1997) who argued that the possession of world-class resources such as sun and sand (beaches in developing countries like Cuba) that have a competitive potential do not always guarantee success in tourism development.

In response to the limitations identified in some of the earlier TDC models, Mazanec et al (2007) developed an explanatory model of competitiveness that derives from and refines the World Travel and Tourism Council's (WTTC) concept of destination competitiveness. The WTTC assessed destination competitiveness using eight dimensions and several indicators (ibid). The eight dimensions include: price, social and economic impact, human resources, social development, environment, technology, infrastructure and openness. In the original model adapted by Mazanec et al (2007), aggregate indices are constructed for each one of the eight dimensions and confirmatory factor analysis is used to determine their weights. The resultant data (estimated weights) makes it possible to construct a composite index of overall competitiveness. Alternatively, the eight main indicators are used directly to construct groups of countries with similar competitive strengths. Mazanec et al, criticize this model for a lack of explanatory perspective, instead refining it through incorporation of cultural heritage, market share and economic growth indicators that are weighted by bilateral distances (geographic location). A structural equation model that includes formative indicators is also presented as a way of dealing with missing data in the WTTC data set used.

The strong interest in assessing TDC by establishing cause-effect relationships in this explanatory model is self-evident. In fact, recent, mostly mathematically-based models of TDC evaluation that have been applied in China (e.g. Yangtze River Delta Region by Zhang et al, 2011 and Hong Kong by Li et al, 2013) are part of this trend that seeks to establish objective assessment of TDC. And yet, Mazanec et al (2007) stress the importance of reliable data and highlight the need for complex software programmes that might be required to compute and hence account for missing data in situations where most countries rarely have complete data on all indicators (of competitiveness) being measured. An unexplored assumption in these mathematical models appears to be that TDC has already been attained to varying degrees, thus necessitating some form of measurement or evaluation. All such observations make it difficult to adopt mathematical or explanatory models to explain the competitive challenges facing a non-traditional destination such as Uganda, if for nothing else, but the fact that access to reliable quantitative data presents its own challenge.

Accordingly, a noteworthy observation by Ritchie and Crouch (2011) that enables some of the above questions to be addressed in this paper encompasses the distinction between aspects of the TDC 
framework that are within the control of the destination (managers) and those beyond their control. Notable examples of the former are the mix of activities, special events and entertainment that form part of the core resources and attractors as well as destination superstructure. Meanwhile, physiography and climate, culture and history as well as the market ties (also key aspects of the core resources and attractors) are considered to be beyond the control of destination managers. Rather than belabour the exigencies of any TDC framework, this paper takes a qualitative shift in perspective, emphasising and re-contextualising the notion of destination competitiveness challenge (hereafter, DCC) as an under researched dimension in this area.

\subsection{MATERIALS AND METHODS: STUDY CONTEXT AND DESIGN}

\subsection{Uganda: General Overview}

Uganda is a landlocked country that lies astride the equator (figure 1 below), and is precariously located at the heart of the African plateau (Ndyabahika \& Bakama, 2010). The great earth movements of the past 30 million years, commonly associated with the separation of the African continent from the Arabian Peninsula also created an extensive rift system known to this present day as the East African (sometimes Afro-Arabian) rift system (Britannica.com). Uganda is thus sandwiched between the East African rift valley to the east and the west, bordered by Kenya to the east, Tanzania to the south, Rwanda to the south west, and Congo (DRC) to the west and the newly formed republic of South Sudan to the north. Despite its disadvantageous location, Uganda has complex geomorphologic characteristics that can be seen in the varying relief features, extensive swamps, forests and large water bodies (Doornkamp, 1968; Taylor \& Howard, 1998; Yazidhi, 2010). The geomorphology is thought to be the result of tectonic influences across different geologic epochs. For instance, the Oligocene is mostly associated with the formation of the western rift valley, meanwhile the oldest rocks are thought to be Precambrian in age (Doornkamp, 1968) and some aspects such as the weathered land surfaces are thought to be linked to the Permian era (Taylor \& Howard, 1998).

Subsequently, four different physiographic regions can be distinguished in Uganda, varying between 620 to 5,029 metres (2,034 to 16,499 feet) above sea level (Yazidhi, 2010). Similarly, the climate consists of five identifiable categories, namely, equatorial, modified equatorial, tropical savanna (continental climate) and semi-arid to arid climates (Ndyabahika \& Bakama, 2010). The country's combined geological and climatic history have resulted into the convergence of 'vegetation types found in central, eastern and southern Africa' (Ministry of Tourism, Trade and Industry, (MTTI), 2003a.p.20), particularly around the Rwenzori Mountains National Park. Consequently, Uganda is variously described as 'Africa's botanical big game' (http://whc.unsco.org/en/list/684/), or in former British Prime Minister Churchill's words, "...truly the pearl of Africa" (Chrétien, 2002). 

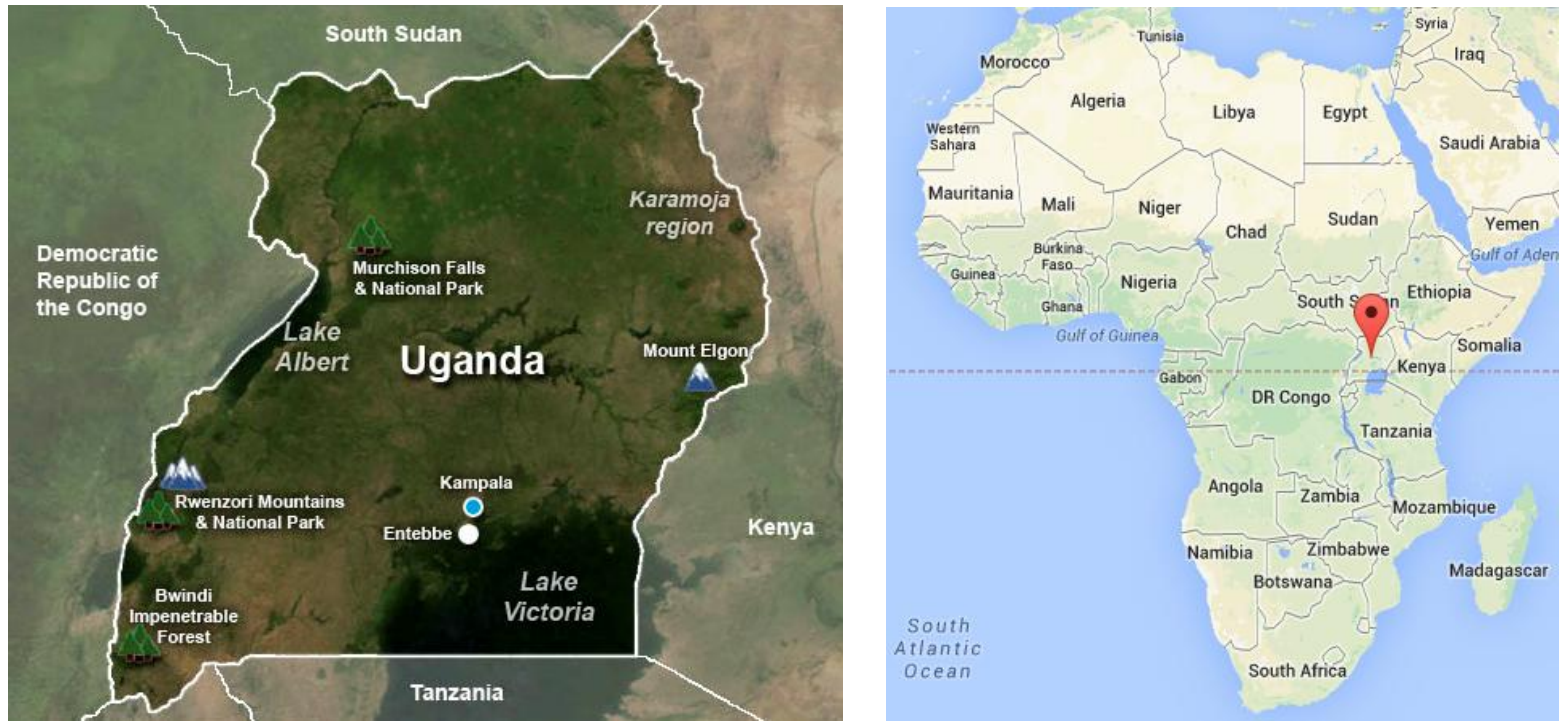

Figure 1: Map of Uganda and Location within the African Continent Source: Our Africa, Google Maps

\subsubsection{Study Context}

Uganda, a former British Protectorate, became independent in October 1962. But the postindependent Uganda, akin to other SSA countries (cf. Teye, 1986) was at various times, entangled in numerous civil wars and coup d'états between 1970 and 2005. The country and its inhabitants (native and foreign) were left dehumanised, dispossessed of human rights, dignity, skilled human resources and confidence, leading to unprecedented loss of lives and property (Chrétien, 2002; Maathai, 2010; Mutibwa, 1992). These tragic historical events although mostly under control since the late 1990s, have not only stifled progress on many fronts, but crucially, they have also defined and constructed the infamous negative image associated with Uganda both within SSA and internationally. To this must be added the recent decision by Ugandan law makers to legislate against homosexuality, a move that has attracted wide spread criticism and condemnation from the international community and the media (e.g. Smith, 2013; Freeman, 2014). Here, Uganda has acquired an unenviable reputation as a country which legitimises homophobia, hence exacerbating the historical negative image problem, although the country's Constitutional Court recently annulled the anti-homosexual law (Smith, 2014), in what appears to be a temporary reprieve.

With a population of over 34M (Uganda Bureau of Statistics, (UBOS), 2013), Ugandan tourism (cf. most countries in SSA), mainly depends on a great diversity of the country's comparative advantage in natural and cultural resources (Ministry of Tourism, Wildlife and Antiquities, hereafter MTWA, 2014; cf. Akama, 1999). Unlike Kenya and Tanzania that have extensive coastlines for beach tourism alongside wildlife tourism, Uganda's tourism industry is mainly small scale and nature-based. It mainly attracts those interested in the rare mountain gorillas, trekking on the snow-capped Rwenzori 
Mountains and bird-watching. These niche forms of tourism are offered alongside the conventional wildlife tourism, and increasingly, water-based adventure tourism (white water rafting). However, the diverse cultural and heritage attractions of the country have not as yet been commercialised for tourism purposes as is the case in the neighboring Kenya for instance (cf. Akama, 2002).

In the late 1980s and early 1990s, a series of measures were taken to revamp the tourism sector that had been severely disrupted by the civil wars of the previous decade during which some wildlife species were hunted to near extinction whilst unprecedented damage to infrastructure were experienced. Key amongst them were the abolition of visa requirements for preferred source markets (the UK, USA etc) and the liberalisation of the economy under the structural adjustment programmes of the International Monetary Fund and the World Bank (Bategeka \& Matovu, 2011; Ministry of Finance and Economic Planning, (MFEP), 1995). Other measures entailed prioritising investments in accommodation and infrastructure (e.g., the main national airport and key road networks), mainly funded by multilateral donor agencies; and, the launching of the tourism master plan that formally led to the introduction of ecotourism in Uganda's protected areas (MFED, 1995). Majority of these measures are currently being revised and new ones pursued in Uganda as discerned from the recent National Development Plan (NDP) (Government of Uganda, (GoU) 2010), Ministerial Policy Statement (MTWA, 2013) and the Background to the National Budget (Ministry of Finance, Planning and Economic Development, (MoFPED), 2014).

Liberalisation and privatisation policies were being pursued with an interest in attracting private local and foreign investment into the economy in general and in tourism in particular. Within the limits of the available data, table 1 below provides an insight into the total investment in Ugandan tourism between 2000-2004 and 2009-2010, of which over 65\% were in hotels, resorts and camping sites. What is clear from table 1 is that the sector is mostly attracting local private investments as opposed to FDI or even joint ventures. However, FDI in tourism may be difficult to assess depending on whether these are investments in equity (with majority or minority control of ownership) or where foreign companies or investors may prefer a leasing agreement, management contracts or franchises instead of direct equity investments (Endo, 2006). This is because national statistics seldom consider non-equity forms of investments as FDI in their reporting (ibid). Besides, several factors are known to influence the nature and volume of FDI attracted into a country (e.g. Morrissey \& Udomkerdmongkol, 2012), making it difficult to comment meaningfully on the limited tourism FDI in Ugandan in the absence of additional information.

The significance of tourism to Uganda's economy can be discerned from the existence of several tourism sector-specific policies that have been formulated, with varying degrees of effective implementation (MTTI, 2003a). Policies, Acts of Parliament and plans such as the Uganda Wildlife 
Policy (of 1999 \& 2014); the Wildlife Act (of 2000); National Tourism Policy (2003-2010); the Tourism Act (of 2008); the NDP (2010-2015) are key examples.

Table 1: Total Investment in Ugandan Tourism (2000-2004, 2009-2010)

Year

Total FDI (US \$)

$\begin{array}{rr}2000 & 1,181,000 \\ 2001 & 1,679,000 \\ 2002 & 688,000 \\ 2003 & 972,000 \\ 2004 & 10,132,000 \\ 2009 & 110,000 \\ 2010 & 11,880,457\end{array}$

Gross

Totals

Total Joint Investment (US\$) Total Local Investment (US\$)

$\begin{array}{rr}400,000 & 6,193,000 \\ 1,700,000 & 5,290,000 \\ 588,000 & 14,064,000 \\ 100,000 & 11,880,000 \\ 22,698,000 & 11,384,000 \\ 250,000 & 1,965,462 \\ 700,000 & 73,316,741\end{array}$

$25,486,000$

$48,811,000$

Source: Former Ministry of Tourism, Trade and Industry, 2010, personal communication

The conservation policies and Acts have culminated into the creation of 'a network of national parks and wildlife reserves (approximating 10\% of the country's total area) to protect the country's wildlife and special landscapes' (MTTI, 2003a, p.20; MTWA, 2014). Table 2 below provides a snapshot of some of the initiatives undertaken by various stakeholders in Ugandan tourism, aimed at developing the sector from a macro and micro perspective. As would be expected in any least developed country (LDC) (cf. Akama 1999), there is a strong influence from the government and donor agencies (mostly top-down), given that the private sector and communities are still under-developed and hence having limited capacity to play the highly desirable leading role. It is here that private sector frustrations with the government's role in such things as marketing and promotion (cf. section 4.2) may be contextualised.

These initiatives (Table 2) have to some extent contributed to Uganda's re-emergence onto the global tourism industry arena, with notable independent verdicts on the destination's uniqueness. For instance, the Lonely Planet recently named Uganda its top destination for 2012. In addition, Uganda has received accolades from other international publications including: Bwindi: Best African Birding Destination (2011) by Travel Africa Magazine and Rwenzori Mountains: One of the World's 15 Best Hikes (2011) by National Geographic Society (World Bank, 2012). Such favourable international recognitions have not yet translated into Uganda's attainment of the much desired tourism competitiveness within the region and globally. Nevertheless the tourism sector holds a potential for diversifying Uganda's economy and for delivering other socio-economic and cultural benefits. 
Table 2: Selected Policy and other Initiatives aimed at developing Tourism in Uganda

\section{Policy and other Initiatives in \\ Ugandan Tourism (1994-2014)}

Tourism Policy (2003-2010)

Uganda Tourism Act (2008)

Uganda National Development Plan (NDP) (2010-2015)

Uganda Tourism Board (UTB)

Uganda Wildlife Authority (UWA)

The Hotel and Tourism Training Institute (HTTI)

Uganda Tourism Association (UTA)

\section{Description}

The first national tourism policy for Uganda formulated under the guidance of a steering committee of key stakeholders from public and private sectors through a participatory and consultative means with a broad range of actors. The aim of the policy was to transform tourism into a major economic sector in Uganda and for Uganda to take part in the development of the ever expanding international leisure and holiday market. This policy expired in 2010 and a new policy is underway to replace it.

An Act of Parliament (the first of its kind) aimed at reforming, consolidating and streamlining the law relating to tourism and aspects such as licensing, regulation and control of the sector, and the effecting of the implementation of the tourism policy of government, reconstitution of the Uganda Tourism Board and so forth

The NDP sets out Uganda's medium term strategic direction, development priorities and implementation strategies. It explicates Uganda's current development status, challenges and opportunities. Its main objective is to accelerate socioeconomic transformation aimed at achieving the National Vision of a transformed Ugandan society from a peasant to a modern and prosperous country in 30 years.

The UTB is a statutory organisation established in 1994 primarily to market Uganda as tourism destination. Its role has been revised and broadened under the new Tourism Act (2008) to promote and popularise Uganda as a viable holiday destination both locally and internationally in order to increase the contribution of tourism earnings to GDP, improve Uganda's competitiveness as an international tourism destination, and increase Uganda's share in the African and World tourism market. In this new role, it is expected to have a wider management responsibility that transcends the previous emphasis on marketing.

UWA is a statutory body established by the Uganda Wildlife Act 2000 although it became operational in 1996 after the merger of the then Game Department with the Uganda National Parks. Its missions is to conserve and sustainably manage the wildlife and the protected areas of Uganda in partnership with neighbouring communities and other stakeholders, for the benefit of the people of Uganda and the global community. It is responsible for the management of 10 National Parks, 12 Wildlife Reserves and 7 Wildlife Sanctuaries and provides guidance over the management of 5 Community Wildlife Areas.

The HTTI was started in the mid 1980s by the government, funded by a UNDP project, with a mission to produce highly skilled and competent workforce for the country's as well as international hospitality industry. Its main objective is to equip the students through specialised training, with requisite knowledge and skills in Hotel Management, Tourism Management, and pastry and Bakery for the hospitality industry. The courses offered are mainly at diploma and certificate (preundergraduate) levels.

UTA is a private sector association of the tourism industry in Uganda. It aims to be the focal point for the tourism private sector and the driving force for tourism's competitive development in the country. Its membership includes: the Board of 
Uganda Community Tourism Projects (year of inception)

- UCOTA (1998)

- COBATI (1998)

- Exposure Africa (1998)

- The National Theatre Craft Village (1993)

- NDERE Centre (1984)

European Union-Uganda Sustainable Tourism Development Programme funded by the European Development Fund (2002-2007)

The Uganda Tourism Expenditure and Motivations Surveys:

- By MTTI ICB-PAMSU

Project (2003)

- By the World Bank (2013)

Uganda Tourism Sector Situational Assessment - World Bank (2012)

United Nations Development Programme (UNDP) (2011-2014)
Airlines Representatives; District Tourism Associations; Hotel and Catering Association of Uganda; Uganda Association of Air Operators; Uganda Association of Tourism Training Institutions; Association of Uganda Tour Operators; the Uganda Association of Travel Agents; the Uganda Community Tourism Association; and, Uganda Safari Guides Association.

Several community-based tourism initiatives have been started by international volunteers and local social entrepreneurs to ensure the participation of the independent and mostly informal, small and medium-sized enterprises in the Ugandan tourism. These projects range from artisanal and handicraft based enterprises (e.g. UCOTA, COBATI, Exposure Africa, and the National Theatre African Craft Villages) to cultural festival and theatre performances (e.g. Ndere Centre). (Thomas et al., 2011).

A project aimed at supporting the sustainable growth and development of tourism in Uganda and to create economic and financial benefits to its stakeholders (local communities, public and private actors). The Project ended due to the perceived lack of political leadership from the then Ministry of Tourism (Thomas et al., 2011).

Surveys commissioned by the current and former Ministries of Tourism (MTWA \& MTTI) but administered by the World Bank and related projects in Uganda to assess key tourism statistics in the country in 2013 and 2003. The surveys administered to tourists exiting Uganda during the stated years collect data on tourist expenditure, duration of stay, tourist activities, sites visited, levels of satisfaction, and suggestions for improvements in the sector. The aim of these surveys is to generate empirical evidence on Ugandan tourism so as to inform government decisions on ways to increase the contribution of this sector to the growth of the Ugandan economy.

A 2012 tourism sector rapid situational assessment commissioned by the Ministry of tourism and funded by the World Bank and DFID in 2012. The purpose was to provide immediate to short term recommendations which if implemented within 24 months, can propel the sector towards competitiveness and sustained growth.

Status: Completed in 2012, but no formal evaluation reports are as yet available.

The UNDP, working with various local and foreign stakeholders (Ministry of Tourism, UTB, MoFPED, UTA, UHOA, UWA, UNCTAD, UNWTO, ITC etc) has been funding projects aimed at supporting the development of markets in tourism and crucially focusing on the inclusion of the poor and the local communities in tourism (as entrepreneurs, employers, consumers etc). This project is still on-going, with an expected end period of 2014 .

Source: Author (table compiled from a review of the publicly available secondary data on these initiatives and where inaccessible, reference is made to some of the consultancy reports in which they are covered, e.g. Thomas et al., 2011). 
The balance of payments statistics from the central bank (Bank of Uganda, (BoU)) (2013) indicates that for the year 2002, the main export sectors such as coffee, travel and transport and remittances respectively, generated $\$ 96.63, \$ 202.48$ and $\$ 441.82 \mathrm{M}$ to the Ugandan economy and in 2012 , the figures had steadily increased to $\$ 372.5 \mathrm{M}, \$ 1,320.47 \mathrm{M}$ and $\$ 910.32 \mathrm{M}$. The need for diversification is particularly poignant given the mixed nature of the Ugandan economy that closely mirrors many of the LDCs; with a large, rural subsistence agricultural sector and one dominant or few primary export sectors (Colliers \& Gunning, 1999; United Nations Conference on Trade and Development (UNCTAD), 2012). In its annual economic performance report, the MoFPED, (2011) noted that agriculture (that employs over $80 \%$ of the population) only contributed $24 \%$ to the GDP in 2010/2011 financial year whilst industry (manufacturing) and the service sectors contributed 27\% and 49\% respectively.

Besides, the recent World Bank (2013) report on the economic and statistical analysis of tourism in Uganda found that 'the overall impact of tourist expenditures in 2012 was large, contributing to 38 percent of exports and 5.6 percent of GDP, including indirect taxes amounting to 0.5 percent of GDP'(p.18). The same report indicates that for the year 2012, tourism's contribution to the regional GDP was as summarised in Table 3 below. Here, the sector's highest contributions to GDP are to be found in Kenya and Tanzania, although disparities in data sources and reporting styles require some reflection here. For instance, the UBOS statistics on GDP contributions per sector focuses on "hotels and restaurants' and 'transportation and communications' as separate categories. In such cases, the reported GDP contributions for tourism may approximate that for hotels and restaurants, leaving contributions from attractions (e.g. the national parks) in the category of 'other services' in a country where the main tourism product is nature-based.

The same World Bank report has two different figures of tourism's GDP contribution to Uganda, including the $5.6 \%$ quoted from page 18 and $3.7 \%$ found on page 2 (Table 3 below) where comparative regional data is presented. This is where Blake's (2008) observation about data scarcity in East Africa becomes a real challenge for generating accurate information about the sector in Uganda. This also implies that despite the availability of national and regional comparative data from official reports, it is inherently difficult to find consistent and reliable data sources that provide accurate information about tourism's overall contribution to Uganda's economy. Nevertheless, the service sector is playing an increasingly important role in the Ugandan economy, necessitating a close focus on the potential contribution of tourism, a service sector, to the diversification of the economy, although tourism is not explicitly mentioned in the MoFPED report of 2012.

Uganda has recently discovered large petroleum deposits estimated to be around 700M to 3.5B barrels along the pristine Albertine basin in the western arm of the East African rift valley (Kathman \& Shannon, 2011) and the country is in the final stages of starting crude oil extraction and possible 
refinery. Ironically, this same area is not only ecologically sensitive but also holds a significant amount of biodiversity known to be endemic to Uganda and ones that underpin much of her naturebased tourism industry. The official government position on this potential dilemma, as recently expressed by the Minister for Tourism on 7th November 2013 (personal communication) is that of ecological stewardship taking precedence over extractive resource use.

Table 3: Tourism's Contribution to the GDP in Selected East African Countries

Country International Arrivals (2012) *Contributions to GDP (2012)

$\begin{array}{lrr}\text { Kenya } & 1,619,000 & 5 \% \\ \text { Rwanda } & 815,000 & 3.1 \% \\ \text { Tanzania } & 1,04,000 & 4.8 \% \\ \text { Uganda } & \mathbf{1 , 1 9 7 , 0 0 0} & \mathbf{3 . 7 \%}\end{array}$

Source: Arrivals_-UN World Tourism Organization, Tourism Highlights, 2012 Edition

*GDP_-World Travel and Tourism Council, Travel and Tourism Economic Impact 2013 in World Bank report (2013, p.2).

However, the potential contribution of the oil revenues to Uganda's long term development needs to be considered within a wider context that entails inter alia, the unconvincing contribution of oil exports to meaningful development in countries such as Nigeria (Kathman \& Shannon, 2011) and the generally weak institutional framework in place (Bategeka \& Matovu, 2011). This is where the tourism industry requires some attention, but only if it is well planned, developed and professionally managed. Tourism development must be grounded in a clear understanding of critical issues that impinge upon the country's ability to effectively harness the resource base, add value to, and benefit from it. It is the task of this paper to partially contribute to such an understanding.

\subsection{Study Design}

A case study approach has been adopted in this paper, mainly because it entails decisions about the possibility of what to study rather than a methodological choice (Stake, 2005). Specifically, a qualitative case study that relies on a single case is adopted, where there are no attempts at generalisation beyond the particular case, but rather an interest in emphasising what can be learnt from it (Bryman \& Bell, 2011; Stake, 2005). There is however an awareness here of the diverse ways in which the term "case study" is conceived and used in different research contexts (Hammersley, 1990; Piekkari et al., 2009) and where concerns about the conventional discourses on reliability, replicability and validity abound (Bryman \& Bell, 2011; Hammersley, 1990). The pervasive influences of such discourses, which in themselves reflect the positivist and alternative views on what is considered scientific is sometimes reflected in researchers' choice of either quantitative or qualitative approaches (cf. Piekkari et al., 2009). With this in mind, of particular significance to this 
study is the idea that 'understanding human activity [such as tourism] requires that we look at its development over time and at its environment, at the configuration of social factors that make up the situation in which it occurs and the way in which these factors interact' (Hammersley, 1990, p.93).

A qualitative case study approach is therefore considered to be more appropriate in this research as it enables an in-depth analysis and description of the multiple challenges that impinge upon the competitive potential of tourism in Uganda. This way, it is more amenable to answering questions about why and how, despite the existence of a tourism resource base, including unique and rare attractions and numerous and on-going interventions by the government and other stakeholders, the country's tourism potential remains unrealised. This in turn facilitates a deeper understanding of the inherent complexities and also permits a contextualised and particularised explanation of their implications for such a destination's quest for competitiveness (e.g. Lee et al., 2007; Piekkari et al., 2009).

The paper is based on secondary data, given the challenges and constraints linked to obtaining primary data and also the fact that at its current level of development; most of the available information on Uganda's tourism sector is from official sources. Reliance on secondary data as seen in this study is not unusual for such destinations as previous research on the evolution of tourism and strategic analysis in other African destinations have used a similar approach (e.g., Akama, 1999; Mayaka \& Prasad, 2012; Teye, 1986). This study thus draws upon purposively selected official publications on Ugandan tourism that are mostly publicly available, notably, its National Tourism Policy of 2003-2010 and the Tourism Act of 2008 that ratified most of the recommendations in the 2003-2010 Tourism Policy. Other secondary sources from Uganda government, consultancy and relevant international publications relating to the country and its tourism sector are also included, mostly obtained from the former Ministry of Tourism (MTTI, e.g. consultancy reports), UBOS, UNWTO websites (e.g. statistics). The focus on competitive challenges derives from the 2003-2010 Tourism Policy that outlined the main constraints facing the tourism sector of the economy and the aspirations in the recent NDP that aims at 'improving the country's competitiveness to levels comparable to middle income countries' (GoU, 2010, P.4). It must be noted that in Uganda, policy documents can be purchased from the local bookshops and other official publications are increasingly being made available to the public on the relevant government websites.

The Tourism Policy itself evolved from the ten year Integrated Tourism Master Plan (1993-2003) that was developed as part of the wider governmental efforts to revamp the tourism sector following the numerous civil wars and civil unrest of the previous decades (cf. section 3.1.1). In this context, it remains, along with the Tourism Act of 2008, one of the most comprehensive statutory publications on Ugandan tourism thus far. Besides, other relevant policy and statutory publications do not directly focus on tourism even though they form an important part of the regulatory framework (e.g. Uganda 
Wildlife Policy (of 1999 \& 2014); the Wildlife Act (of 2000)) and where they do (e.g. the NDP (2010-2015, pp 99-106), they refer back to the 2003-2010 Tourism Policy and the Tourism Act of 2008, hence demonstrating what is known as inter-textuality (cf. Atkinson \& Coffey, 2004). The latter is a term used to describe the tendency for documents to refer to and/or respond to other documents thereby forming a part of the context or background for their production (ibid). For the stated reasons and also within the idiosyncrasies of qualitative case study research, this paper focuses on the Tourism Policy and to some extent, the Tourism Act, whilst using other relevant policy and official publications for corroboration.

However, given that the current research was contemplated during the final year of the 2003-2010 Tourism Policy, it seemed necessary to find out from key informants in Uganda's tourism, if the challenges described in the 2003-2010 Tourism Policy were still relevant or if indeed newer and different issues were of significance. On this basis, in-depth interviews were conducted with six highly placed tourism sector officials (both private and public sector) in Uganda in August 2010. These interviews were held with senior officials of: the former Ministry of Tourism, (MTTI) with average experience of seven years; Uganda Tourism Board (UTB) with average experience of 11 years, and Uganda Tourism Association (UTA) with average experience of 17 years. Two additional informal interviews were held in London during the World Travel Market Exhibition in November 2012 and five held with tourists departing Uganda at the end of June 2014. It should be noted that although a handful of community tourism associations exist, that attempt to represent the mostly small and predominantly female owned tourism businesses (handicrafts, restaurants and lodges) (Thomas et al., 2011), the tourism industry in Uganda is fairly small but tightly coordinated by a few, well integrated elite firms (Christian \& Mwaura, 2013).

Data analysis in this study drew insights from the theoretical and methodological perspectives adopted for the study. This strategy is considered to be a powerful aid in guiding analysis as it helps in pointing out where and on what should attention be focused (cf. Robson, 2002; Tonkiss, 1998). Given their prevalence in qualitative research (cf. Bryman \& Bell, 2011; Miles \& Huberman, 1994), a combination of content and thematic analysis formed the basis of data analysis in this study. For instance, having reviewed the literature on TDC and opting to recontextualise this in terms of DCC, analytic strategy focused on constantly sifting, comparing and contrasting the various ways in which themes related to challenges and constraints to Ugandan tourism emerged from the data (both secondary and primary) (cf. Tonkiss, 1998). Such an approach that requires a thorough and detailed examination of textual data is most effective when dealing with a limited body of data (Silverman, 2005).

Within the secondary data, therefore, specific focus was placed on the complete textual passage or a paragraph or theme that clearly and explicitly articulated the nature and scope of challenges faced by 
Uganda's tourism (cf. Silverman, 2005). In this sense, the specific units of analysis entailed selected words and word classes, phrases (e.g. 'image', 'negative image', 'tourism marketing', 'stakeholders', 'tourism budgets', regulation', 'tourism development' 'institutional capacity' etc) or statements that analytically embodied the discursive attributes of the challenges of tourism development and management in Uganda and how these were represented in the selected textual passage (cf. Bryman \& Bell, 2011). Similarly, interview transcripts were critically reviewed to identify what themes emerge from the key informants' view of the contextual challenges facing Ugandan tourism (ibid; cf. Miles \& Huberman, 1994).These were compared and contrasted with themes that had been developed from the secondary data. The themes from the transcripts that clarified or corroborated what were specified in the policy documents were selected for further analysis.

What is presented in the study findings is therefore consistent with Bryman and Bell's (2011, p.624) observation that 'this process of [identifying key themes] may account for the prominence given to some themes over others when writing up the fruits of qualitative data analysis'. The limitation here is that issues that were not covered in the policy documents and/or those that did not receive adequate attention (from interviewees and policy documents) have either been omitted or touched upon indirectly in this paper. For instance the Tourism Policy did not cover challenges related to ICT at all. Although the NDP and the budget speech of 2013-14 cover this topic and it was highlighted during the interviews, none of the key informants (excepting one), considered it to be an important challenge in the face of other pressing problems. Two other themes that were thought to be relevant in this study but later on omitted for the same reason, include regionalisation (given the pace at which the East African region is pursuing socio-economic integration) and local community involvement in tourism. The challenges associated with local communities as identified by the Tourism Policy entailed 'their lack of awareness and appreciation of their tourism resources and development potential.... Inadequate communication and collaboration between local communities and the central/national organisations...' (MTTI, 2003a, p.2; cf. Thomas et al., 2011). But the challenges of getting in touch with the umbrella Community Tourism Associations or their individual members and also the fact that most of the community tourism enterprises operate in the informal sector made it difficult to obtain primary data on this otherwise important sector (cf. Thomas et al., 2011). This experience, coupled with the lack of adequate coverage of this issue in the interviews (excepting references to the challenges of licensing and monitoring the informal sector and standards of service delivery) meant it could not be covered directly in section 4 .

The analysis presented in section 4 below therefore focuses on those challenges which had been identified in the 2003-2010 Tourism Policy and confirmed during the interviews and author's experiential knowledge as still being the main challenges facing the Ugandan tourism. These challenges have been re-contextualised in terms of the TDC and other relevant Ugandan and SSA literature to develop an in-depth insight into the issues. Such an analysis will most likely face 
common criticisms leveled against case study approach; particularly those rooted in the lack of a scientific basis for generalisation (e.g., Yin, 2009). But as would be expected in such a qualitatively driven study, no attempts are being made here to generalise the findings and analysis of this study in the conventional, positivistic sense (cf. Lee et al., 2007). It is therefore emphasised that the goal of the case study analysis presented in this paper is to concentrate on the uniqueness of the situation in order to develop an in-depth and contextual understanding of its complexity (Bryman \& Bell, 2011), whilst generating theoretical insights and debates that may, analytically, be transferable to similar cases (Yin, 2009).

The knowledge claims made in this paper should therefore be judged on the basis of the transparent way in which the design, analysis and presentation have been explained and rationalised (e.g. Seale, 1999) as well as the appropriateness criterion that engenders the concept of authenticity (e.g. Guba \& Lincoln, 1989; Lincoln \& Guba, 2003). Here, ontological and educative authenticities are particularly relevant. The former entails the view that research should enable those affected to develop a more sophisticated understanding of the phenomenon under investigation while the latter is about "determining a raised level of awareness.... by individuals about those who surround them or with whom they come into contact for some social or organisational purpose"' (Lincoln and Guba 2003:278). In sum and within the limitations mentioned previously, the findings present one plausible and authentic account of the competitive challenges facing Uganda's tourism at the macro level.

\subsection{RESULTS}

This section begins by referring to the observations made in the 2003-2010 Tourism Policy which are summarised in vignette 1 below.

Vignette 1 encapsulates some of the profound challenges facing Uganda with regard to the demand for, development of, and effective marketing and management of the tourism sector. These issues have been shown to persist to this day and are thus explored further in this analysis, starting with a reflection on the current trends in Ugandan tourism.

Vignette 1: Current status, constraints and limitation in Uganda's tourism
...Tourism has not developed as expected, despite the fact that the country has many potential touristic attractions. The strength of tourism in Uganda is the unspoilt wilderness areas, the gorillas; the rich culture and the special combination of nature and culture... Even under these circumstances revenue from the services sector (mainly tourism), as indicated in the Balance of Payment Statistics by the Bank of Uganda made up 115 million USD [\$] in year 2001 ahead of coffee with 107 million USD. However, this income is largely derived from business visitors and domestic tourism, rather than international pleasure tourists visiting national parks and staying in private lodges.... What has held tourism back is the problem of insecurity and the poor image of Uganda as a tourism destination ....' (MTTI, 2003, p.1-2). 


\subsection{Tourism in Uganda: Current Trends}

The World Economic Forum's (WEF) travel and tourism competitiveness report for 2013 ranks Uganda the $13^{\text {th }}$ overall competitive destination in SSA out of a selection of 31 destinations in that region and $116^{\text {th }}$ in the world out of 139 countries (Blanke \& Cheasa, 2013). These reports which have been compiled since 2007 compare countries based on three broad sub indexes of regulatory framework, business environment and infrastructure and human, cultural and natural resources (ibid). The regulatory framework and the business environment remain some of the pressing challenges identified both in the Tourism Policy (MTTI, 2003a) and in the recent WEF report, thus limiting Uganda's capacity to realise her full tourism potential. Despite these challenges, and also notwithstanding the methodological constraints inherent in collecting and compiling tourism statistics (Blake, 2008; Massieu, 2003), the country has witnessed a steady increase in tourism arrivals in the last few years (see Table 4 below). In fact, it has exceeded the national Tourism Policy objective (MTTI, 2003a, P.ii) of 'increasing arrivals from 200,000 to 500,000 in a ten year period' (2003-2013) by $140 \%$.

Table 4 also provides a summary of what can loosely be described as some of the most competitive destinations within SSA in terms of tourist arrivals. The general trend in table 4 is that of a steady increase in annual international arrivals to these destinations. With the exception of Ethiopia, the increase in arrivals remains modest in some of the destinations, interlaced with periods of minor to significant decreases. The 2008 global financial crisis might partly explain the observed decline in arrivals between 2008 and 2010 for a majority of the countries, although in the case of Kenya, the post election violence of 2007 and the recurrent incidents of perceived terrorist attacks may also be a factor. Within the greater EA region, Tanzania and Uganda represent the most remarkable increases in arrivals, from just fewer than 600,000 in 2005 to a little over 1,000,000 in 2012. The trends in Rwanda are also significant insofar as it is a very small country within the EA region. It is unsurprising for South Africa (the most advanced economy on the African continent) and Kenya (one of the most well developed and marketed destinations in Africa) to receive most of the tourists to the sub-continent. But Zimbabwe presents an interesting paradox given its ongoing political and international relations challenges. However, such statistical data can be misleading if not viewed critically and contextually. For instance, although international arrivals have continued to increase in Uganda relative to regional competitors, international receipts have mostly lagged behind throughout the period.

Whilst the currency exchange differentials between the Uganda Shillings and three of the main foreign currencies used in the country (US dollars, British Pound Sterling and the Euro), may explain the low receipts, these differences also highlight an issue with the nature and scope of demand for the 
destination. For instance, the average expenditure by different categories of tourists who spent at least one night in Uganda in 2012 stood as follows: leisure tourists ( $\mathrm{n}=68,100,6.8$ nights), $\$ 1,211$; business and meetings ( $\mathrm{n}=164,500$ and 60,700, with 4.4 and 5.2 nights respectively), $\$ 871$ and $\$ 929$; cultural ( $\mathrm{n}=6,600 ; 6.1$ nights), $\$ 1,179$ and family ( $\mathrm{n}=121,000,5.7$ nights), $\$ 539$ (World Bank, 2013, p.8).

Table 4: Tourist Arrivals ('000s): Selected Destinations in Sub-Saharan Africa (2005-2013)

$\begin{array}{lrrrrrrrrc}\text { Country } & \mathbf{2 0 0 5} & \mathbf{2 0 0 6} & \mathbf{2 0 0 7} & \mathbf{2 0 0 8} & \mathbf{2 0 0 9} & \mathbf{2 0 1 0} & \mathbf{2 0 1 1} & \mathbf{2 0 1 2} & \mathbf{2 0 1 3} \\ \text { Ethiopia } & 227 & 290 & 312 & 330 & 427 & 468 & 523 & 596 & \text { N/A } \\ \text { Kenya } & 1,536 & 1,644 & 1,686 & 1,141 & 1,392 & 1,470 & 1,760 & 1,619 & \text { N/A } \\ \text { *Rwanda } & - & - & 710 & 765 & 646 & 619 & 688 & 815 & \text { N/A } \\ \text { S. Africa } & 7,369 & 8,396 & 9,090 & 9,592 & 7,012 & 8,074 & 8,339 & 9,188 & 9,510 \\ \text { Tanzania } & 590 & 628 & 692 & 750 & 714 & 754 & 843 & 1,043 & \text { N/A } \\ \text { Uganda } & \mathbf{4 6 8} & \mathbf{5 3 9} & \mathbf{6 4 2} & \mathbf{8 4 4} & \mathbf{8 0 7} & \mathbf{9 4 6} & \mathbf{1 , 1 5 1} & \mathbf{1 , 1 9 7} & \mathbf{1 , 2 0 6} \\ \text { Zambia } & 699 & 757 & 897 & 812 & 710 & 815 & 920 & 859 & \text { N/A } \\ \text { Zimbabwe } & 1,559 & 2,287 & 2,508 & 1,956 & 2,017 & 2,239 & 2,423 & 1,794 & 1,833\end{array}$

Source: UNWTO TOURISM HIGHLIGHTS 2006, 2008, 2009, 2011, 2012 \& 2014; UNWTO Compendium Statistics, 2012

*Overnight, non-resident visitors and same day visitors-excursionists for Rwanda

For other countries, figures refer to inbound tourism statistics, overnight, non-resident visitors only

One possible argument therefore is that of strong demand from mostly low-spending tourists and the implication in terms of competitiveness in this sector. But to what extent do comparative statistics, reports and the ensuing, arbitrary numerical rankings facilitate an in-depth understanding by destinations such as Uganda, of the challenges facing them whilst embarking on tourism development and its perceived benefits?

Table 5: International Tourist Arrivals \& Receipts in Uganda 2004 - 2011

$\begin{array}{rrr}\text { Year } & \text { Arrivals (thousands - '000') } & \text { Receipts (Millions - US\$) } \\ 2004 & 512 & 266 \\ 2005 & 468 & 380 \\ 2006 & 539 & 309 \\ 2007 & 642 & 398 \\ 2008 & 844 & 498 \\ 2009 & 807 & 667 \\ 2010 & 946 & 784 \\ 2011 & 1,150 & 1,400 \\ 2012 & 1,197 & 1,600\end{array}$

Source: UNWTO Tourism Highlights (2006, 2008, 2009, 2011 \& 2012) \& UBOS, Statistical Abstract (2012, 2013) 


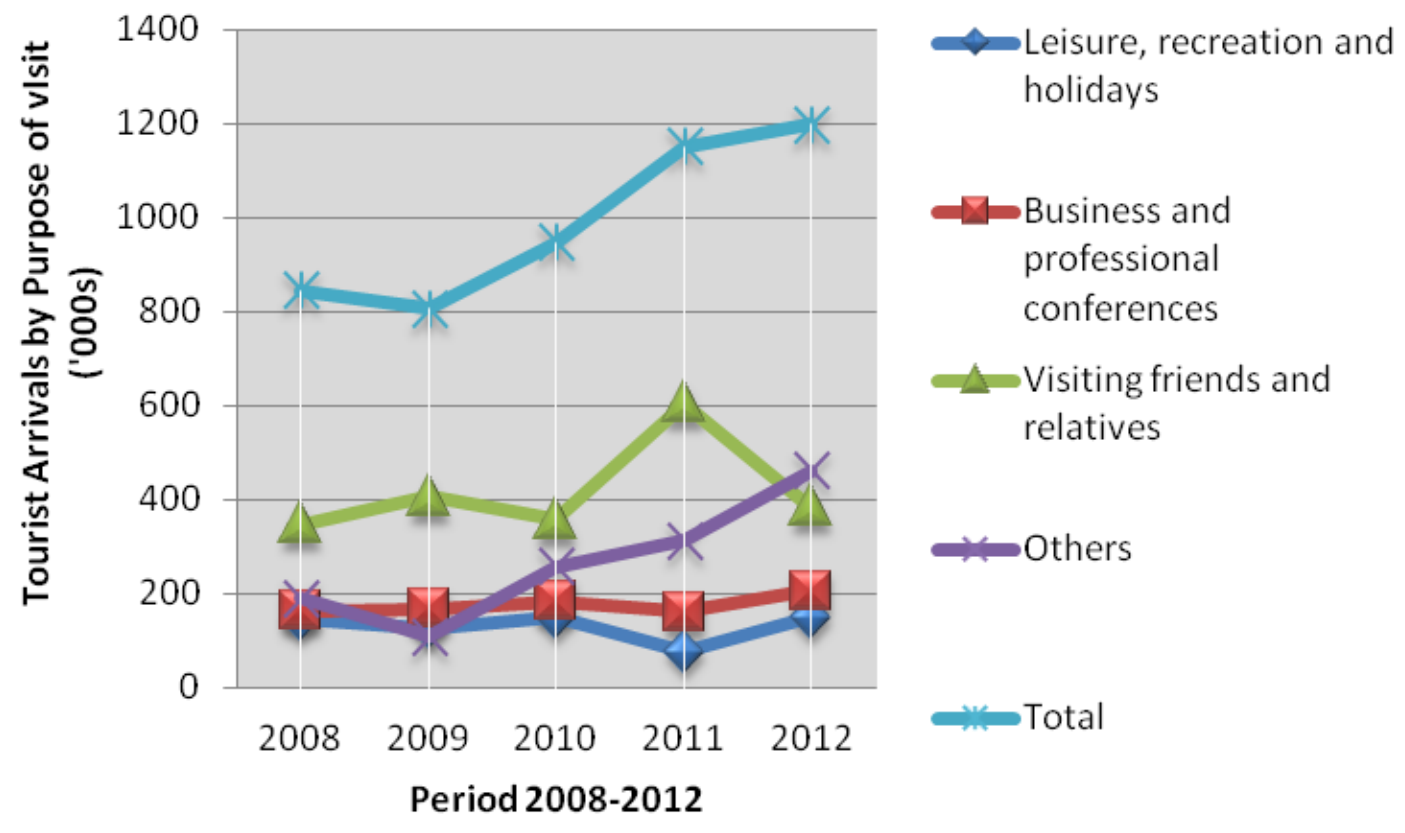

Figure 2: Tourist Arrivals by purpose of visit ('000s), 2008 - 2012

Source: Ministry of Internal Affairs and Uganda Bureau of Statistics (2013)

Although the overall tourist numbers and expenditure continue to increase steadily (refer to table 5 above), there remains a sharp contrast in the purpose of visitation to Uganda (figure 2 above). The majority of tourists who visit Uganda come from within the African region, notably from Kenya, Rwanda, South Sudan, Tanzania and Congo (DRC), accounting for $78 \%$ of all non-resident arrivals in 2012 meanwhile the preferred source markets of the US and the UK accounted for 5\% and 3.5\% respectively of the total arrivals during the same period (UBOS, 2013; World Bank, 2013). So that in comparison with Kenya and Tanzania where most tourists visit for leisure purposes, the VFR (excepting 2012) and business travelers segment dominate in Uganda (figure 2 above) (UBOS, 2013; cf. Vignette 1 above). In other words, there is a disparity between the target market for the main tourism product and the type of tourists attracted to Uganda. The leisure holiday makers who are interested in niche tourism (gorillas and birds) combined with the traditional wildlife safaris (the "Big 5") remains the main target market that also corresponds well with the historical evolution of tourism demand in the EA region (cf. Akama, 1999; Harrison, 2000).

Several consultancy and donor-funded reports (e.g. MTTI, 2003b; TTC, 2004; Thomas et al., 2011; World Bank, 2012, 2013) attribute this disparity in demand patterns to several factors. Notably, the poor visibility and inadequate marketing of destination Uganda, poor infrastructure and customer service as well as the negative perceptions of the destination (cf.3.1.1) by mostly European and North American markets, from where the leisure and cultural tourists originate. Whilst holding an informal interview with five international tourists departing from Entebbe International Airport in June 2014, some of these issues that typify competitive challenges in Uganda resurfaced. One of the female 
respondents offered a reasonably deep insight into her motivations for visiting Uganda and the ensuing experiences, noting that:

....I have been visiting popular parts of Africa since early 2000 and I never thought about Uganda. But in 2009, I decided to take time off my regular job in a travel and tour agency in North America to do some charitable work in Uganda.... It is when I begun to appreciate how different and exciting the country was..... So this time round, I came for holidays, but after some reflection... I realised I want to set up my own [tourism] business here, and try to reach the North American market as many people there only focus on the well-known African countries, yet look what we [pointing to the others] have discovered?... (Interview held on 24th June 2014).

This group of five middle-aged N. American tourists all seemed reasonably satisfied with their Ugandan experience, given that all but one were visiting the country for the second time during which they brought one other friend. When asked if they had encountered any issues during their visit to Uganda, and what if any suggestions they might give Ugandans to improve the tourism sector, two of the respondents retorted:

...The only slight problem is that the roads leading to the rural parts and the national parks are... quite uncomfortable... The traffic jam in Kampala is, ... impossible and irritating? ...Also customer service was sometimes just not what we expected... I can understand [poor customer service] for the people we encountered in the rural parts but not from the formal businesses... I guess that is something that really could be looked into? (ibid).

Such opinions, although not representative in any conventional sense, suffice to reiterate the previously highlighted view that one of the pressing challenges undermining Uganda's quest for competitiveness entails the twin problem of poor (road) infrastructure and perceived poor customer service (e.g.cf., Thomas et al., 2011; World Bank, 2012, 2013). These views resonate well with the tourism sector in the country that feels the government is not doing enough to develop tourism. But crucially, they highlight instances where inadequate availability of supporting factors and resources impede tourism development within the destination (cf. Ritchie \& Crouch, 2011). Nevertheless, it would be unwise to disregard the trend that shows an increasing proportion of VFR and business travelers mostly from SSA as are apparent within the Ugandan tourism statistics. Questions ought to be asked about Uganda's insistence on attracting the European and N. American leisure market in the light of the current demand patterns in order to assess if indeed this is the best approach for the destination.

The current failure to broaden the leisure market base to include the native (mostly middle class) Ugandans and other Africans through a dedicated product for domestic and regional tourism remains 
a supply-side competitiveness challenge. This is particularly poignant given that Europe, the most competitive tourist destination according to the WEF report, which received a total of $51 \%$ of the over one billion international tourist arrivals in 2012 (UNWTO, 2013), has to her credit, a very healthy demand from within the domestic and regional population. Although the socio-economic, political and cultural factors in Europe and Uganda do not lend themselves to a fair comparison, some trends in Uganda indicate how adaptable the mostly youthful population is. For instance anecdotal evidence shows how ordinary Ugandans are embracing mobile phones and mobile money technology despite having no previous experience with conventional phones, bank accounts and similar transactions. Increasingly also, leisure activities such as motor racing that draws participants from different parts of Africa organised by the Federation of Motorsport Clubs of Uganda, attract record numbers of Ugandans of different walks of life. These examples highlight, alongside the increasing proportion of VFR and business travelers from mostly within Africa, the existence of potential markets that are waiting to be explored. Crucially, they demonstrate how, a wider perspective on leisure-based tourism, one that embraces the local and regional demand for Uganda is currently lacking.

The VFR and business travel segments require attention, given the need for developing and nurturing marketing ties (defined as 'the process by which a destination establishes and builds linkages with residents of the tourist originating countries') with the origin countries (Ritchie \& Crouch, 2011, p.341). In terms of the marketing ties, Ritchie and Crouch make an important observation in the TDC framework by explaining that such linkages evolve over time, and that 'ethnic ties resulting from immigration patterns that have evolved over time provide the strongest and perhaps most enduring predictable travel flows to a destination'. They add that 'although the VFR segment of the travel market is not necessarily the most profitable segment, [it] provides a firm foundation for building tourism within a destination' (ibid). It is apparent that the reference to limited profitability of the VFR segment is what seems to frustrate the Ugandan tourism sector that focuses on attracting mostly the leisure holiday makers who are considered to be the high spenders (e.g. MTTI 2003a, b; World Bank, 2013).

However, research into the VFR segment demonstrates its important contributions to the Australian, New Zealand, USA and UK tourism sectors (Backer, 2012), particularly during times of uncertainty such as the recent and on-going economic recession. Such contributions are grounded in the fact that the VFR segment, unlike the leisure holiday travelers, are mostly unimpeded by fluctuations in the external environment based on their motive for travel. Given the discovery of oil and the possibility of new business opportunities, alongside the macroeconomic policies that focus strongly on attracting FDI into the country, the prospects for an upward increase in business travel as well as VFR should not be underestimated. One could add here, a potential demand from Ugandans in the Diaspora, who 
are already making a notable contribution to the economy through annual remittances. A long term vision might also include a speculation about the possibility of a number of SSA countries attaining middle income status, which in itself could go along way into addressing the endemic challenges of geographic and cultural distance from the currently preferred source markets and other challenges related to prolonged negative image. For these reasons, the increases in the VFR segment should be celebrated rather than being derided in the face of the limited budgetary support for effective marketing of the country, and the challenges associated with marketing destinations with prolonged negative image (cf. Avraham \& Ketter, 2013).

\subsection{Institutional and Managerial Capabilities}

In addition to the competitive challenges encompassing overall demand for destination Uganda (cf. 4.1), one must add the inadequate institutional and managerial capability both from the public and private sectors as depicted in vignette 2 below. Managerial capability underpins the ability to envision what and where a destination would like to be in the medium to the long term, and, crucially, how this vision can be attained within the context of past and current position (cf. Teece 2007). It has, as an essential feature, the requirement that the main stakeholders are clearly identifiable and that they know how they ought to operate individually and collectively in order to achieve their goals and the wider vision (cf. Bornhorst et al., 2010; Dredge, 2006; Ritchie \& Crouch, 2011; Kimbu \& Ngoasong, 2013). In the case of Uganda, the managerial capability has been mostly inadequate as identified in vignette 2, and also reiterated in the recent NDP (GoU 2010) as being a national, rather than sectorspecific challenge. Within the context of the current research, it poses competitive challenges at three main levels.

First, despite its newly legitimated role as the DMO, the UTB struggles to discharge its managerial duties in the most effective and efficient way (personal communication, 2010, 2012). The current approach to destination management is top-down and mostly influenced by the structure and composition of the UTB as defined by the Tourism Act (GoU, 2008; cf. Kozak \& Baloglu, 2010). The board comprises two political appointments by the Minister (representing the Tourism and Finance Ministries), three representatives of ostensibly independent public sector organisations (Uganda Civil Aviation Authority, Uganda Wildlife Authority and National Planning Authority), an ex-officio and five other members appointed from representatives of the tour operators, accommodation owners/hoteliers and catering service providers, private aviation sector and an organisation that is considered to be representative of the tourism sector (GoU, 2008, p.6). The UTB structure thus reflects a fair balance between public and private sector stakeholders, but with strong involvement of the Ugandan public sector in its management. There is no directly discernible involvement of local communities or non-governmental organisations. This however is not unusual in contexts where the 
private sector is small, not very well grounded and experienced and also where meaningful democratic representation is still emerging but not yet well-developed.

Vignette 2: Institutional and managerial constraints in Uganda's tourism

...the institutional capacity of both the public and private sectors is inadequate to initiate tourism development.... By and large, the public sector tourism functions have been understaffed with limited financial and human resource capacity. In this situation, the private sector feels that Government does not provide full political support for the development of the tourism sector. For its part, the private sector has been fragmented without the necessary joint resources to form a leading role in tourism development. Despite these problems, the private sector has undertaken some crucial investments in lodges and facilities. However, the low number of tourists has led to underutilization of the facilities and very poor financial performances. The sector has established a number of tourism associations, including the umbrella Uganda Tourism Association. However, the membership support and overall capacity are limited (MTTI, 2003a, P.1-2 cf. GoU, 2010, P.27-).

The UTB is mostly bogged down by budgetary constraints, which according to two senior officials during interviews in 2010 and 2012, tends to be one of the lowest in the region. To emphasise the point, a very senior member of UTA, in a separate interview trenchantly remarked that

The government does not understand what tourism is about...the government does not understand the importance of having a positive image, positive national image...You do not just do a single campaign and expect the whole world to know... Kenya spends about US\$15 million per year on campaigns...on CNN, TripAdvisor...in Europe at train stations ... you see them, they are visible, that is what campaigns mean.....It is not just one million US \$ investment and over nine years, we are still talking about the same thing... (Interview held on $20^{\text {th }}$ Aug. 2010)

Similar sentiments have recently been attributed to two senior officials of the UTB (the Chief Executive Officer (CEO) and head of Marketing) by a government owned newspaper, the New Vision (online, dated 22 July 2014) that reported on their appearance before the Ugandan Parliamentary Committee on Trade, Tourism and Industry. The newspaper contradictorily quoted these officials, remarking that 'whereas in this financial year Kenya has allocated \$35M and Rwanda \$17M on promoting tourism, Uganda has allocated $\$ 700,000^{\prime}$ (attributed to the head of Marketing)...while the CEO 'commends the government for increasing the UTB budget from $\$ 350,000$ to $\$ 2 M$ ' but emphasises the need to rise up to the level of these two neighbouring countries with which Uganda has signed an agreement for joint promotion. Such comparisons with neighbouring countries have garnered support from Ugandan legislators on the said Committee who, according to the same media reports 'appealed to the government to increase the budget for tourism promotion to match the competition in the regional and international markets...' 
These examples highlight the magnitude of the budgetary constraints facing the Ugandan DMO (cf. Pike, 2013), although they ought to be viewed against the backdrop of the wider context of the countries concerned. For instance, Kenya is a lower-middle income country (UNCTAD, 2012) that has a heavy involvement of foreign multinational corporations in her tourism sector (e.g. Akama \& Kieti, 2007) and the country has until recently been mostly peaceful. Uganda on the other hand is a LDC that for a long time was trapped in numerous civil wars and coup d'états (cf. section 3.1.1), with adverse consequences, of which the chronic problem of negative image and low tourism FDI still persist to this day. Although it is not unreasonable to expect more commitment from Uganda, this and other contextual differences between the countries must be borne in mind, given their mediating role in determining the outcomes of such an investment.

Besides, the relatively limited national budget allocated to the UTB has seen a steady increase in tourist arrivals and expenditure, albeit of the "wrong" segment of the market (cf. 4.1).

The positive outcomes resulting from meager resource investments in the face of several other national priorities might be the reason the government does not see a justification for increasing expenditure in this area. This however contradicts the view that 'government macroeconomic policies largely depend on the relative importance of individual sectors within a destination' (Zhang et al., 2009 , p.348). This is a contradiction insofar as there is a contrast between the prominence given to tourism in the most recent NDP, the renewed political status where there is a fully-fledged tourism ministry in Uganda and the overall budgetary support to the sector. This Ugandan contradiction corroborates what Beritelli et al (2014, p.404) describe as 'the problem of fickle actors'. They highlight that 'a study carried out with a series of prominent actors in various destinations has shown that individuals agree on the challenges of the destination (often general issues), while they clearly show different perceptions of the competitive advantages and the competitors of the destination'.

Vignette 3: Private Sector Role and Organisational Structure

The private sector shall play a leading role in future tourism development. For the sector to undertake this role, it is essential that the sector develops a strong organizational structure with the participation of all major tourism stakeholders and that the sector improves its professionalism and general capabilities. The private sector will undertake the necessary investments and will ensure, through competition, that the sector is financially viable. The private sector will also have a social obligation as it will ensure that tourism will be a major contributor to poverty alleviation and the sector will ensure a sustainable development, including involving local communities in tourism development. (MTTI, 2003a, p.14-15).

However, for the UTB and the private sector to effectively address the problem of tourism development and management in Uganda they require reasonable amounts of funding. This would then make it possible to achieve one of the main objectives of the 2003 Tourism Policy with regard to 
private sector role and organisational structure in Uganda's tourism as summarised in vignette 3 above. What remains a challenge in terms of managerial and institutional capability in such situations boils down to the question of resource allocation particularly by the public sector, something a senior UTB official suggests the government is oblivious to, noting that 'money breeds more money' and that 'annual budget should rise with increased tourism revenue generated in a given period' (interview held on $19^{\text {th }}$ August 2010).

The establishment of the tourism levy and the tourism development fund under sections 20 and 21 of the 2008 Uganda Tourism Act (GoU, 2008) has been singled out as a possible remedy to the budgetary constraints. This strategy entails a private-sector driven role in addressing funding shortages (cf. vignette 3 above; cf. MTTI, 2003b; TTC, 2004). However, there is a perceived political influence-peddling by unstated individuals who are seen to be interfering with the work of the UTB in such a way that 'there is reluctance to pass into law, policies that may favour tourism development and this has negative impacts such as the tourism levy that is supposed to be contributed by all tourism business to the UTB to fill in the funding gap. This one has been sat upon by politicians' (interview held on $8^{\text {th }}$ August, 2010).

While there are no independent verifications of the alleged political influence, it is also clear from speaking to some individual members of the tourism private sector in the country, that there is a strong resistance towards the levy. These individuals argue that the tourism levy, if implemented, will make the destination less price competitive and exacerbate the demand related challenges discussed in 4.1 above. Ironically, some comparatively expensive destinations such as the USA, Switzerland and Dubai charge tourism levies or similar (municipality or local state) taxes without necessarily undermining demand dynamics. Here, it is clear that tourism development like other sectors of international trade flourishes best in contexts where the economy is well-developed (Lea, 1988; Endo, 2006). The tourism levy has thus far, not been implemented, hence a stalemate in terms of addressing the budgetary problem.

Such challenges necessitate the existence of unambiguous managerial competence at different levels of the tourism organisational structures and hierarchy. Stamp (1981, p.19) conceptualised managerial competence in terms of '... sensing where a problem might lie, recognising it, defining it, constructing a solution to it and being ready to refine that solution in the light of change in the problem itself or in the circumstances which surround it'. One way of demonstrating managerial competence within this Ugandan context will be for the UTB as a DMO to collaboratively work with key stakeholders to critically reflect on and evaluate the past five decades of tourism development in the country. This will ensure that (new) benchmarks for unlearning practices that have not been productive and relearning new or modified competences are introduced as an important stepping stone for gaining 
competitive advantage. But none of this will be meaningful if there is no stakeholder commitment and collaboration (cf. Bornhorst et al., 2010; Buhalis, 2000; Dredge, 2006; Kimbu \& Ngoasong, 2013). A noteworthy competitive challenge in this Ugandan context encompasses the complexity associated with multiple stakeholders with disparate and potentially conflicting interests (cf. Buhalis, 2000; Dredge, 2006; Kimbu \& Ngoasong, 2013). This is the second level at which managerial capability challenges can be explicated. Such stakeholder challenges can be illustrated by two main examples. First, although the Tourism Act of 2008 has mandated the UTB to handle licensing of new and existing tourism businesses in the country (a role that was previously played by the Ministry of Tourism), the licensing of accommodation and similar facilities in Uganda's wildlife protected areas remains the mandate of UWA (see table 2). During the interviews, it emerged that there have been controversies around the way UWA issues licenses; specifically that it continues to protect pioneer operators who are not keen to have competition, in direct contravention of the 2003 policy pronouncements (cf. vignette 3 above). This issue mentioned by nearly all the interviewees in 2010 is best illustrated by the remarks of the Uganda Hotel Owners Association (UHOA) which succinctly explains that

...one issue holding back camp and lodge development within some parks is the fact that existing operators enjoy exclusive rights. Clearly these could be justified in the past in order to encourage investors to build lodges in parks which had comparatively few visitors. But as the number of tourists has increased, these rights are regarded by some as a restraint on bed capacity. There is now a balance to strike between the rights of pioneering operators and those who wish to follow... (UHOA, 2010, p.5).

Similar observations have been made elsewhere. In a donor-funded research that sought to capture the gains of the Ugandan tourism sector through a value chains analysis, Christian and Mwaura (2013) focused on the largest national park in the country (Murchison Falls National Park, hereafter MFNP), and asserted in their findings, that

...the growth of Uganda's tourism global production network is... slow and characterised by a few elite firms and highly controlled travel through tightly coordinated distribution channels... tourism firms pursed vertical and horizontal economic upgrading strategies but social upgrading outcomes were mixed. Social upgrading for permanent workers followed economic upgrading for hotels and tourism service providers in MFNP, but not for community members outside the park. Several aspects such as the role of UWA concessions... are... influencing upgrading dynamics (p.2).

These observations that highlight an example of market failure in tourism and ones that have a connectedness with managerial and institutional capability challenge have important implications. That is, they are stifling Uganda's private (tourism) sector's social contribution to poverty alleviation as articulated in vignette 3 above and also tourism's potential for inclusive, pro-poor growth and 
development in the country (cf. Thomas et al., 2011). This particular challenge not only makes it inherently difficult for a proper managerial structure to function but most importantly, it undermines and weakens efforts to form and effectively harness the power of public and private partnerships that are known to be essential for destination competitiveness (cf. Bramwell, 2011; Dredge, 2006; Kimbu \& Ngoasong, 2013), but ones that are currently not well established in Uganda.

Secondly, one interviewee in the former Ministry of Tourism observed that

...Americans are very much interested in our gorilla [tourism], but we implement too many conservation policies and procedures around gorilla permits which make the waiting list grow. For those who can't wait, they will go to Rwanda. I do not understand why we protect these things [mountain gorillas] so much and yet they can bring us a lot of tourist dollars in the process..., (interview held on $2^{\text {nd }}$ Aug. 2010).

This excerpt clearly illustrates the challenges associated with the priorities given to conservation of wildlife and biodiversity over unsustainable expansion of tourism. Although Uganda is famed for its rare mountain gorillas, the fragility of this endangered species implies that permits are issued to very few tourists at a time, who can then visit the two gorilla parks (in Mgahinga and Bwindi). This same dilemma has made it difficult for Uganda to be marketed by especially some top European Tour Operators that prefer to promote mass market destinations. Both UWA and UTB have chosen natural resource stewardship over mass tourism, clearly to the disenchantment of those who see such an approach denying Uganda the much needed economic and social development (cf. Burns, 2004).

At the third level, individual capability challenges undermine the competitive potential of destination Uganda. In an interview with another very senior member of the UTA, it was clear that knowledge and skills gap continues to be a major challenge for the tourism industry in the country, despite the formal tourism and hospitality education offered at Uganda's main public and private universities and other tertiary institutions (cf. GoU, 2010, p.29). He asserts that "tourism graduates (sic) in Uganda do not understand what it means to serve in the tourism industry... It is not surprising that there are no Ugandan tourism managers in hotels of $3^{*}$ and above..." (Interview held on $16^{\text {th }}$ August 2010). This observation (cf. 4.1 and the departing tourists) highlights the challenges linked to the meaning and essence of commercialised hospitality and excellence in customer service provision, hence constituting part of the systemic issues facing Uganda's tourism. To this must be added the classic education and training dilemma where tourism employers strongly perceive a mismatch between graduate education and training and their needs as employers, a situation that is not limited to Uganda (e.g. Ayikoru et al., 2009). Unsurprisingly, the NDP has identified inadequacy of human resources (quality and quantity) as one of the key constraints undermining Uganda's development (GoU, 2010). Meanwhile the MoFPED (2013) signposted public sector intervention in tourism development 
through, among other things supporting skills training of critical tourism sector human resources including the re-construction of the UHTTI (table 2).

Although the focus here is on the employee competence, further reflection on the tourism entrepreneurs and employers themselves is warranted. An insightful observation to this effect comes from a senior Tourism Development Officer at the former ministry of Tourism, who observed that

This sector of our economy has too many informal businesses. This makes it difficult to enforce any standards of service provision and monitor who is doing what. This is a big problem for us in the Ministry, we have so far not been able to license and monitor all tourism businesses in the country ... but we have structures and procedures in place that we use for those registered businesses (Interview held on $6^{\text {th }}$ Aug. 2010).

This again is not unusual, the global tourism industry is mostly characterized by small and medium sized enterprises and tends to be highly fragmented (Buhalis, 2000). However, research into tourism employment characteristics indicates a strong reliance on unskilled and semi-skilled labour force and unwillingness on the part of the industry to recruit graduates into the workforce (e.g. Baum, 2007). To this must be added the question of whether or not all or most of the employers themselves have a very good grasp of the nature and scope of the industry and the dynamics of demand and supply (cf. 2.0) within the context of a non-traditional destination. It would appear the problem is both systemic and endemic, rather than being narrowed down to employee knowledge.

\subsection{CONCLUSIONS AND FUTURE RESEARCH}

The overarching argument in this paper is that the term competitiveness used in everyday academic sense is rather problematic when applied to non-traditional tourism destinations such as Uganda. Such destinations face multiple challenges that are both endemic and systemic in nature, which in turn stifle their ability to effectively develop and benefit from their relatively unique and valuable core tourism and other resource base (cf. Crouch \& Ritchie, 1999; Ritchie \& Crouch, 2011; Barney, 1991; Teece, 2007). Subsequently, and in spite of the observed positive trends in quantifiable aspects, the tourism industry in such destinations remains non-competitive (cf. 3.1.1 and 4.1). The complexity arising from the contextual nature of such challenges is exacerbated by the sector's failure to adapt to constantly evolving contemporary trends in the global tourism industry (cf. Claver-Cortes et al., 2007; Buhalis \& Law, 2008; Xiang \& Gretzel, 2010; Sparks et al., 2013) and potential demand from domestic and regional segments of the market. These issues collectively reveal an under-achievement in the tourism sector, based initially on the destination's resource potential. Additionally, the set of pull factors (e.g., geographic proximity to key source markets, accessibility to such markets, close cultural links with preferred source markets) (Weaver \& Lawton, 2010; Ritchie \& Crouch, 2011) exacerbated by endemic features (e.g. geographic location) and systemic weaknesses (e.g. the level of developments 
in infrastructure and tourism superstructure, inadequate institutional and managerial capacity) all detract from their quest for competitiveness (cf. Kimbu, 2011).

Accordingly therefore, such non-traditional destinations, rather than stretching their mostly meager resources to attain what seems unattainable, could instead concentrate on the competitive parity (Barney, 1991) they are able to achieve. This would, within the Ugandan context, entail a closer focus on particularly the business and VFR segments, including an exploration of the potential in Diaspora, regional and domestic leisure markets. In other words, it implies concentrating on tourism development and management that in the medium term, enables them to survive in the market without an illusion of attaining and sustaining competitive advantage. This, however is less about saying such destinations should not seek competitiveness. Rather, it is about adding a critical voice to research that has already demonstrated that the focus on tourist volume and value statistics in seemingly successful destinations, seldom accounts for the extent to which such countries benefit from tourism (cf. Akama \& Kieti, 2007; Mwaura \& Ssekitoleko, 2012). Moreover, when imports, remittances by expatriate owners of key sub-sectors, risk of capital flight and weak linkages with the local economy are taken into account (ibid), competitiveness that widely benefits such destinations becomes a distant reality.

This current research therefore reiterates the need to take a critical, case-by-case investigation into the extent to which the notion of competitive advantage appropriately applies to non-traditional and other developing countries' tourism sectors. Such an approach encourages research to look beyond the sometimes overly enthusiastic estimates of positive trends in tourism arrivals and expenditure statistics and the usual optimistic future growth prospects in order to provide appropriate scholarly and policy support to such destinations in developing and managing their tourism resources. This in turn is more likely to facilitate them in attaining meaningful qualitative and quantitative benefits from the sector as defined by their own priorities and the extent to which these can be achieved through tourism.

In terms of contextual issues for Uganda, several initiatives, including recent ones have been taken to address some of the crucial systemic challenges linked to poor infrastructure (e.g. GoU, 2010; MoFPED, 2013) and also rating of hotels (MTWA, 2014). But these are long term investments whose benefits might trickle in slowly. Besides, extensive marketing as advocated by various parties in Ugandan tourism (4.2), although highly desirable, does not and cannot override the causes and consequences of negative image. It is prudent to suggest that more focus should be placed on addressing the systemic challenges that are within the control of the destination (cf. Kimbu, 2011). Examples here can include the infrastructure, institutional, managerial and individual capabilities as well as the situational factors that generate the negative image in the first instance (civil wars, homophobia etc). Such efforts require long term investments which if undertaken, could potentially 
reduce the consequences of the endemic challenges linked to, for instance, geographical and cultural distance from the preferred source markets.

Further research will therefore be required to investigate the causes and consequences of deficiencies in institutional and programmatic activities implemented by various tourism stakeholders in the country (cf. Kimbu \& Ngoasong, 2013), aimed primarily at the European and the North American leisure markets. As has been shown in 4.1, this market segment constitutes less than $10 \%$ of the currently known demand for Uganda but remains the main focus of the tourism sector in the country. While the economic rationale for such a strategy is understandable for an LDC, more empirical research is needed to understand how the scope may be expanded to accommodate other currently untapped potentials such as the Diasporas, domestic and regional leisure markets. This will paint a better picture of where and how to begin to effectively address the demand-related challenges identified in this research and other official publications (cf. 4.1).

Additionally, further investigation is required to examine the observed concerns with employee knowledge and skills and their perceived effects on service delivery. Most service excellence advocates identify customers as being both 'internal and external' to the organisation and emphasise the significance of meeting their needs as a way of realising their full potential (e.g., Anderson \& Zemke, 1991; Hudson \& Hudson, 2013). Specific questions need to be asked about the terms customer and service excellence and how these are understood and implemented by both tourism employers (entrepreneurs) and employees. Questions about human resource policies and strategies and whether or not these exist and are integrated with the overall strategy of the tourism organisations in question will also be useful to investigate in the Ugandan context. Finally on this same issue, it will be useful to critically evaluate the efficacy of internships or work placement elements of (tourism and hospitality) courses that are often compulsory at most higher education institutions in Uganda from all stakeholder perspectives. This will make it possible to identify what, if any gaps exist in education and training and what prospects exist for collaboration and effective use of work place mentorship to address the challenges linked to individual capability. 


\section{References}

Agarwal, S. (2002). Restructuring Seaside Tourism: The Resort Lifecycle. Annals of Tourism Research, 29, 25-55.

Akama, J.S. (1999). The Evolution of Tourism in Kenya. Journal of Sustainable Tourism, 7 (1), 6-25.

Akama, J. S. (2002). The Role of Government in the Development of Tourism in Kenya. International Journal of Tourism Research, 4 (1), 1-13.

Akama, J., \& Kieti, D. (2007). Tourism and Socio-economic Development in Developing Countries: A Case Study of Mombasa Resort in Kenya. Journal of Sustainable Tourism, 15(6), 735748.

Anderson, K., \& Zemke, R. (1991). Delivering Knock Your Socks off Service (revised edition). New York: Amacom.

Anholt, S. (2007). Competitive Identity: The New Brand Management for Nations, Cities and Regions. Basingstoke: Palgrave Macmillan.

Atkinson, P., \& Coffey, A. (2004). Analysing Documentary Realities. In: D. Silverman (Ed.) Qualitative Research: Theory, Method \& Practice (2nd edn.). London: Sage.

Avraham, E., \& Ketter, E. (2013). Marketing Destinations with Prolonged Negative Images: Towards a Theoretical Model. Tourism Geographies, 15 (1), 145 - 164.

Ayikoru, M., Tribe, J. \& Airey, D. (2009). Reading Tourism Education: Neoliberalism Unveiled. Annals of Tourism Research, 36 (2), 191-221.

Azarya, V. (2004). Globalization and International Tourism in Developing Countries: Marginality as a Commercial Commodity. Current Sociology, 52(6), 949-967. DOI:

$10.1177 / 0011392104046617$

Backer, E. (2012). VFR Travel: Why marketing to Aunt Betty matters. In: H. Schanzel, I. Yeoman \& E. Backer, (Eds.), Family tourism: Multidisciplinary Perspectives (pp.81-93). Bristol: Channel View Publications.

Bank of Uganda (2013). Bank of Uganda Analytical Data, available at http://www.bou.or.ug/bou/rates_statistics/statistics.html (accessed on 24 Nov. 2013)

Barney, J.B. (1991). Firm Resources and Sustained Competitive Advantage. Journal of Management, 17 (1), 99 - 120.

Bategeka, L., \& Matovu, J.M. (2011). Oil Wealth and Potential Dutch Disease Effects in Uganda. Economic Policy Research Centre, Makerere University, 1-30.

Baum, T. (2007). Human Resources in Tourism: Still Waiting for Change. Tourism Management, 28 (2007): 1383 - 1399.

Beeton, S. (2005). Book Reviews. Tourism Management 26, 291-300. 
Beritelli, P., Bieger, T., \& Laesser, C. (2014).The New Frontiers of Destination Management: Applying Variable Geometry as a Function-Based Approach. Journal of Travel Research, 53(4), 403417. DOI: $10.1177 / 0047287513506298$.

Blanke, J., \& Cheasa, T. (2013) (Eds.) The Travel and Tourism Competitiveness Report 2013: Reducing Barriers to Economic Growth and Job Creation. Geneva: World Economic Forum, available at: www.weforum.org/ttcr

Blake, A. (2008). Tourism and Income Distribution in East Africa. International Journal of Tourism Research, 10, 511-524. DOI: 10.1002/jtr.702.

Bornhorst, T., Ritchie, B.J.R., \& Sheehan, L. (2010). Determinants of Tourism Success for DMOs and Destinations: An Empirical Examination of Stakeholders' Perspectives. Tourism Management, 31 (5), 572 - 589.

Bramwell, B. (2011). Governance, the State and Sustainable Tourism: A Political Economy Approach. Journal of Sustainable Tourism, 19 (4-5), 459-477.

Bryman, A., \& Bell, E. (2011). Business Research Methods (3rd ed.). Oxford: Oxford University Press.

Buhalis, D. (2000). Marketing the Competitive Destination of the Future. Tourism Management, 21, 97 - 116.

Buhalis, D., \& Law, R. (2008). Progress in Information Technology and Tourism Management. 20 Years on and 10 Years after the Internet- The State of eTourism Research. Tourism Management, 29, $609-623$.

Burns, P. (2004).Tourism Planning: A Third Way? Annals of Tourism Research, 31 (1), 24 43.

Claver-Cortes, E., Molina-Azorin, J. F., \& Pereira-Moliner, J. (2007). Competitiveness in Mass Tourism. Annals of Tourism Research, 34 (3), 727-745.

Colliers, P., \& Gunning, J.W. (1999). Why has Africa grown slowly? The Journal of Economic Perspectives, 13 (3), 3-22.

Chrétien, J. (2002). The Great Lakes of Africa: Two thousand years of history (translation by Scott Straus). Brooklyn: MIT Press.

Christian, M., \& Mwaura, F. (2013). Capturing the Gains: Economic and Social Upgrading in Tourism Global Production Networks: Findings from Uganda. Working Paper 19, February 2013, available at: http://www.capturingthegains.org/pdf/ctg-wp-2013-19.pdf.

Crouch, G.I, \& Ritchie, B.J.R. (1999). Tourism, Competitiveness and Societal Prosperity. Journal of Business Research, 44, 137-152.

Crouch, G.I. (2011). Destination Competitiveness: An Analysis of Determinant Attributes. Journal of Travel Research, 50(1), 27-45. DOI: 10.1177/0047287510362776.

De Holan, P.M., \& Phillips, N. (1997). Sun, Sand and Hard Currency Tourism in Cuba. Annals of Tourism Research, 24(4), 777-795. 
Doornkamp, J.C. (1968). The Role of Inselbergs in the Geomorphology of Southern Uganda. Transactions of the Institute of British Geographers, 44, 151-162.

Dredge, D. (2006). Policy Networks and the Local Organisation of Tourism. Tourism Management, 27, 269-280.

Dwyer, L., Edwards, D., Mistilis, N., Roman, C., \& Scott, N. (2009). Destination and Enterprise Management for a Tourism Future. Tourism Management, 30, 63-74.

Dwyer, L., Mellor, R., Livaic, Z., Edwards, D., \& Kim, C. (2004). Attributes of Destination Competition: A Factor Analysis. Tourism Analysis, 9 (1-2), 91-101.

Dwyer, L., \& Kim, C. (2003). Destination Competitiveness: Determinants and Indicators. Current Issues in Tourism, 6 (5), 369-414.

Endo, K. (2006). Foreign Direct Investment in Tourism: Flows and Volumes. Tourism Management 27, 600-614.

Enright, M. J., \& Newton, J. (2004). Tourism Destination Competitiveness: A Quantitative Approach. Tourism Management 25, 777-788.

Freeman, Colin (2014). Have US Evangelists Helped to Inspire Uganda's Anti-gay Laws? http://blogs.telegraph.co.uk/news/colinfreeman/100261161/have-us-evangelists-helped-to-inspireugandas-anti-gay-laws/ (accessed on 1 August 2014).

Government of Uganda, (2008). The Uganda Tourism Act, 2008, ACTS SUPPLEMENTS No. 2 to The Uganda Gazette No. 25 volume CI dated 9th May 2008. Entebbe: UPPC, Government Printers.

Government of Uganda (2010). The National Development Plan (2010/11-2014/15). Entebbe: Government Printers, April 2010.

Guba, E. G. \& Lincoln, Y. S. (1989) 'Fourth Generation Evaluation’. London: Sage.

Gunn, C. (1994). Tourism Planning. ( $3^{\text {rd }}$ edn.) New York: Taylor and Francis.

Hassan, S.S. (2000). Determinants of Market Competitiveness in an Environmentally Sustainable Tourism Industry. Journal of Travel Research, 38, 239-245.

Hammersley. M. (1990). The Dilemma of Qualitative Method: Herbert Blumer and the Chicago Tradition. London: Routledge.

Harrison, D. (2000). Tourism in Africa: The Social and Cultural Framework. In: Dieke, PUC. (Ed.), The Political Economy of Tourism Development in Africa (pp.37-51). New York: Cognizant Communication.

Hudson, S., and Hudson, L. (2013) Customer Service for Hospitality and Tourism. Oxford: Goodfellow Publishers.

Kathman, J., \& Shannon, M. (2011). Oil Extraction and the Potential for Domestic Instability in Uganda. African Studies Quarterly, 23-45.

Keller, P. (1998). Destination Marketing: Strategic areas of Inquiry. Reports of 48th Congress, 40 (pp. 9-22). St-Gall: AIEST. 
Kimbu, A.N. (2011). The Challenges of Marketing Tourism Destinations in Central African Sub region: The Cameroon Example. International Journal of Tourism Research, 13, 324-336.

Kimbu, A.N., \& Ngoasong, M.Z. (2013). Centralised Decentralisation of Tourism Development: A Network Perspective. Annals of Tourism Research, 40, 235-259.

Kozak, M \& Baloglu, S. (2011). Managing and Marketing Tourist Destination: Strategies to gain a Competitive Edge. New York: Routledge.

Lea, J. (1988). Tourism and Development in the Third World. London: Routledge.

Lee, B., Collier, P.M., \& Cullen, J. (2007). Reflections on the Use of Case Studies in the Accounting, Management and Organizational Disciplines. Qualitative Research in Organizations and Management: An International Journal, 2 (3), 169-178.

Lincoln, Y. S. \& Guba, E. G. (2003) 'Paradigmatic Controversies, Contradictions and Emerging Confluences', In: N.K. Denzin \& Y.S. Lincoln, (eds.) The Landscape of Qualitative Research: Theories and Issues, (2 ${ }^{\text {nd }}$ edn), (pp. 253-291). Thousand Oaks: Sage.

Massieu, A. (2003). A System of Tourism Statistics (STS): Scope and Content. In: Tourism Statistics: International Perspectives and Current Issues, Lennon, J., Ed., pp.3 - 13. Delmar:

CENGAGE Learning.

Mazanec, J.A., Wöber, K., \& Zins, A.H. (2007). Tourism Destination Competitiveness: From Definition to Explanation? Journal of Travel Research, 46, 86-95.

Mbaiwa, J., E. (2005). Enclave Tourism and its Socio-economic Impacts in the Okavango Delta, Botswana. Tourism Management, 26, 157-172.

Ministry of Finance, and Economic Planning. (1995). Background to the Budget 1995/1996. Government of Uganda, Kampala, Uganda.

Ministry of Finance, Planning and Economic Development. (2012). Annual Economic Performance Report 2010/2011. Available at: http://www.finance.go.ug/index.php?option=com docman\&Itemid=106\&limitstart=5, retrieved on $10^{\text {th }}$ January 2012

Ministry of Finance, Planning and Economic Development (2014). Background to the Budget, 2014/15 Fiscal Year (PDF), available at: http://www.finance.go.ug/ (accessed on 13 August 2014).

Ministry of Tourism, Trade and Industry, (2003a). Tourism Policy for Uganda. Kampala: MTTI.

Ministry of Tourism, Trade and Industry, (2003b). Consolidated Low and High Expenditure Motivation Survey Report 2003. Kampala: MTTI ICB-PAMSU Project.

Ministry of Tourism, Wildlife and Antiquities (MTWA) (2013).Ministerial Policy Statement 2013-14. Kampala: MTWA.

Ministry of Tourism, Wildlife and Antiquities (2014).Uganda Wildlife Policy: Policy on Conservation and Sustainable Development of Wildlife Resources. Kampala: MTWA. 
Morrissey, O., \& Udomkerdmongkol, M. (2012). Governance, Private Investment and Foreign Direct Investment in Developing Countries. World Development, 40(3), 437-445.

Mwaura, F. \& Ssekitoleko, S. (2012). Reviewing Uganda's Tourism Sector for Economic and Social Upgrading. Economic Policy Research Centre, Makerere University, Research Series No.91, June, 2012, available at: http://www.eprc.or.ug/pdf_files/series91.pdf, accessed on 10 ${ }^{\text {th }}$ Feb. 2014.

Ndyabahika, M., \& Bakama, B. (2010). Climate of Uganda. In: B. Bakama (Ed.), Contemporary Geography of Uganda (pp.18-33). Dar-es-salaam: MKUKI NA NYOTA.

Piekkari, R., Welsh, C., \& Paavilainen, E. (2009). Case Study as Disciplinary Convention: Evidence from International Business Journals. Organisational Research Methods, 12 (3), 567-589.

Pike, S. (2013). Book Reviews. Tourism Management 34, 247-253.

Porter, M. (1990). Competitive Advantages of Nations. New York, NY: The Free Press.

Ritchie, B.J.R., \& Crouch, G.I. (2011). A Model of Destination Competitiveness and Sustainability. In: Y. Wang, \& A. Pizam (Eds.), Destination Marketing and Management: Theories and Applications (pp.326-339). Wallingford: CABI.

Ritchie, B.J.R., \& Crouch, G.I. (2003).The Competitive Destination: A Sustainable Tourism Perspective. Oxon/Wallingford: CABI

Seale, C. (1999) The Quality of Qualitative Research. London: Sage.

Silverman, D. (2005). Doing Qualitative Research: A Practical Handbook. London: Sage.

Smith, David (2014). Uganda Anti-gay Law Declared 'Null and Void' by Constitutional Court. http://www.theguardian.com/world/2014/aug/01/uganda-anti-gay-law-null-and-void (accessed on 1 August 2014).

Smith, Erin Conway (2013). Uganda Passes Anti-gay Bill available at: http://www.telegraph.co.uk/news/worldnews/africaandindianocean/uganda/10531563/Uganda-passesanti-gay-bill.html (accessed on 1 August 2014).

Sparks, B.A., Perkins, H.E., \& Buckley, R. (2013). Online Travel Reviews as Persuasive Communication: The Effects of Content Type, Source, and Certification Logos on Consumer Behavior. Tourism Management 39, 1-9.

Stake, R. (2005). Qualitative Case Studies. In: N.K. Denzin \& Lincoln, Y.S. eds., The Sage Handbook of Qualitative Research (3rd Edn.), (pp. 443-466). London: Sage.

Stamp, G. (1981). Levels and Types of Managerial Capability. Journal of Management Studies, 18 (3), 277-297.

Taylor, R.G., \& Howard, K.W.F. (1998). Post-Palaeozoic Evolution of Weathered Land Surfaces in Uganda by Tectonically Controlled Deep Weathering and Stripping. Geomorphology 25, 173-192

Teece, D. J. (2007) 'Explicating Dynamic Capabilities: The Nature and Microfoundations of (Sustainable) Enterprise Performance'. Strategic Management Journal 28(13), 1319-1350. 
Thomas, F., Barya, G., \& Katongole, S. (2011). Opportunity Study: Inclusive Tourism Programme. International Trade Centre, ITC, available at http://www.visituganda.com/informationcentre/research/files/ITC Opportunity study Uganda.pdf (accessed on 30 December 2013).

Tonkiss, F. (1998).Analysing Discourse, In: C. Seale, (ed.), Researching Society and Culture (pp. 245-260). London: Sage.

Tourism and Transport Consult International, (TTC), (2004). Uganda Sustainable Tourism Development Programme-UGSTDP Project No.8 ACP/UG 37: Marketing Strategy 2004-2008. Dublin: TTC.

Uganda Bureau of Statistics (UBOS) (2013). Statistical Abstracts. Entebbe: UPPC, Government Printers, available at: http://www.ubos.org/onlinefiles/uploads/ubos/pdf\%20documents/abstracts/Statistical\%20Abstract\%2 02013.pdf.

Uganda Hotel Owners Association (UHOA), (2010). Uganda Hotel Guide. Cholchester: Land and Marine Publications Ltd.

UNWTO, (2013). Tourism Highlights, 2013 Edition, available at: http://dtxtq4w60xqpw.cloudfront.net/sites/all/files/pdf/unwto highlights13 en lr 0.pdf (accessed on 8 Feb 2014)

Vanhove, N. (2012). The Economics of Tourism Destinations (2nd ed). London: Elsevier.

Weaver, D., \& Lawton, L. (2010). Tourism Management ( $4^{\text {th }}$ edn.). Milton: Wiley.

World Bank (2013). Economic and Statistical Analysis of Tourism in Uganda: Washington, DC: The World Bank Group. Publicly available at: http://wwwwds.worldbank.org/external/default/WDSContentServer/WDSP/IB/2013/07/26/000356161 20130726 154446/Rendered/PDF/797680WP0Touri0Box0379789B00PUBLIC0.pdf . Accessed on 20 December 2013.

Xiang, Z., \& Gretzel, U. (2010). Role of Social Media in Online Travel Information Search. Tourism Management, 31, 179-188.

Yazidhi, B. (2010). Geomorphology of Uganda. In: B. Bakama (Ed.), Contemporary Geography of Uganda (pp.35-50). Dar-es-salaam: MKUKI NA NYOTA.

Yin, R. (2009). Case Study Research: Design and Methods ( $4^{\text {th }}$ edn). Thousand Oaks, California: Sage.

Zhang, H., Gu, C., Gu, L., \& Zhang, Y. (2011). The Evaluation of Tourism Destination Competitiveness by TOPSIS \& Information Entropy: A Case in the Yangtze River Delta of China. Tourism Management, 32 (2), 443-451.

Zhang, J., \& Jensen, C. (2007). Comparative Advantage: Explaining Tourism Flows. Annals of Tourism Research, 34 (1), 223-243.

Zhang, X., Song, H., \& Wang, G.Q. (2009). Tourism Supply Management: A New Research Agenda. Tourism Management, 30, 345-358. 